\title{
Synthesis and Applications of Inorganic Materials Derived from Aluminium Smelting Waste
}

\author{
by \\ MD HAIRI, Siti Noor Syazana \\ School of Chemical and Physical Science \\ Victoria University of Wellington
}

\begin{abstract}
A thesis
Submitted to the Victoria University of Wellington

In partial fulfillment of the requirements of the degree of

Master of Science in Chemistry

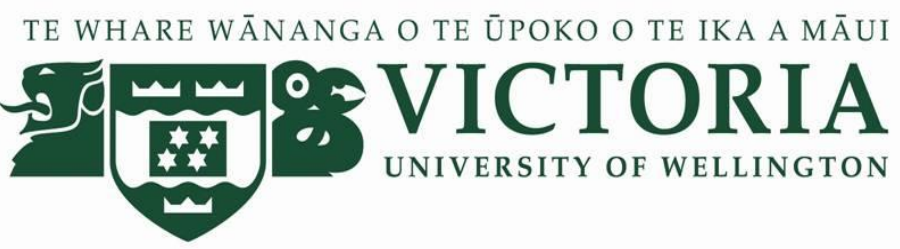

Victoria University of Wellington 


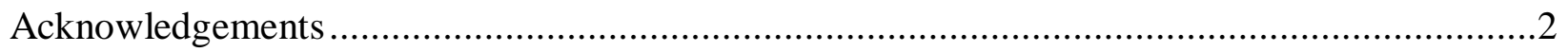

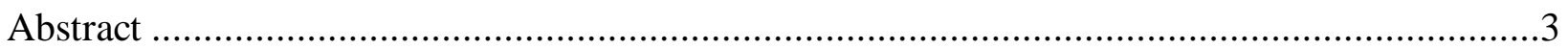

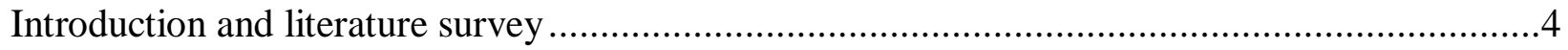

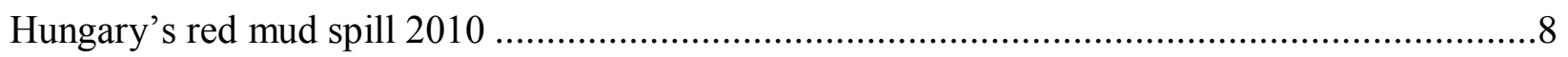

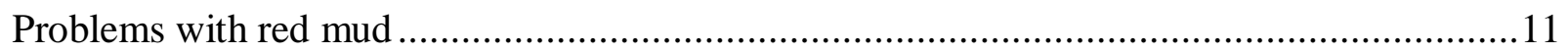

Geopolymers as substitutes for Ordinary Portland Cement (OPC)........................................14

Factors influencing geopolymer formation from red mud and red mud mixtures.........................15

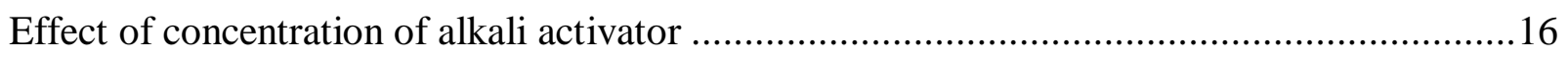

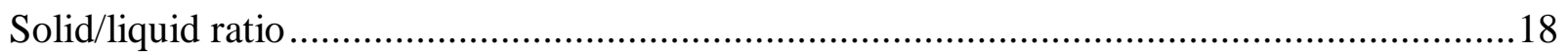

Geopolymers from materials with high Fe content ………..............................................20

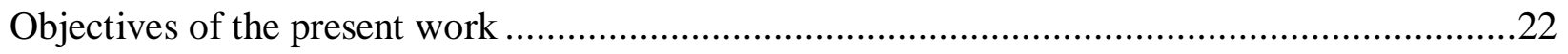

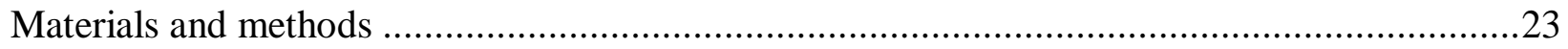

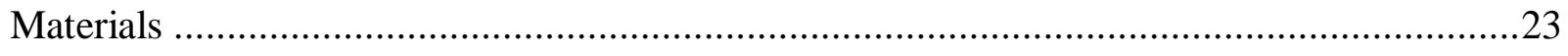

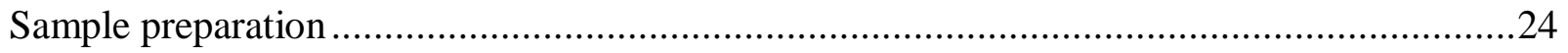

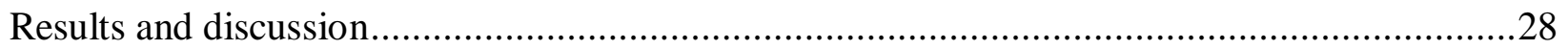

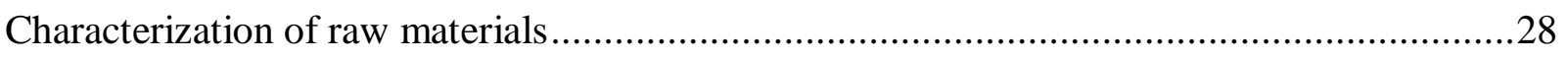

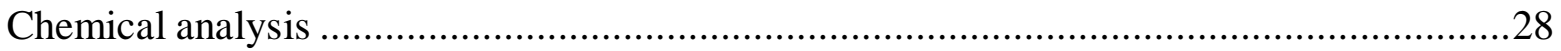

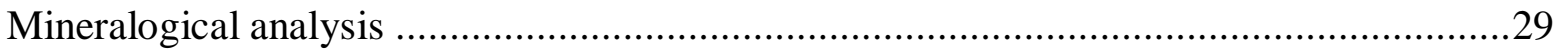

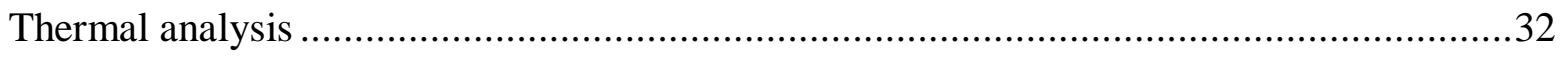

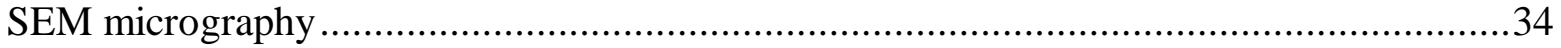

Characterization of the geopolymer samples ......................................................................... 35

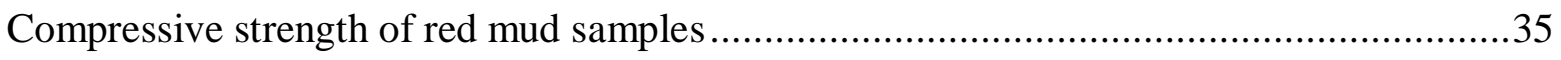

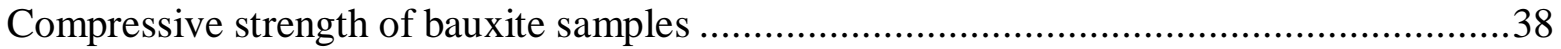

Mineralogical analyses .............................................................................................

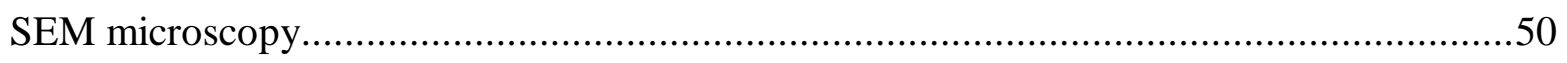

NMR spectroscopy of red mud geopolymers ................................................................5

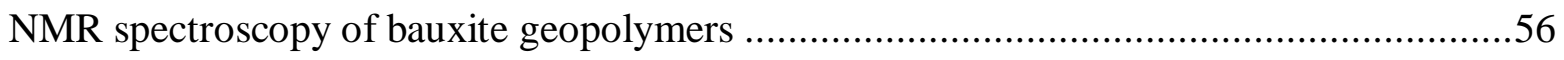

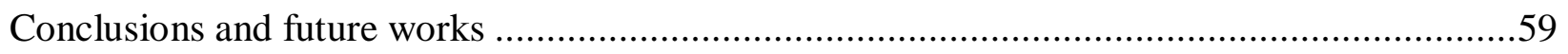

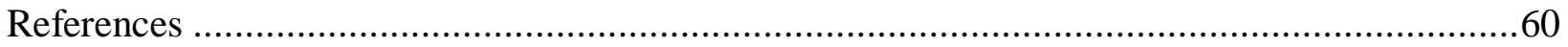




\section{Acknowledgements}

I would like to express my deep gratitude to Prof Kenneth MacKenzie, my research supervisor for his patient guidance, enthusiastic encouragement and useful critiques of this research work. His willingness to give his time so generously has been much appreciated. Special thanks should be given to MARA, my government funding agency for funding me in furthering my Master degree. Without the help of this scholarship, I would not been able to complete my study abroad.

I am indebted to Prof. Ray L. Frost of the Queensland University of Technology (QUT) for supplying the bauxite sample, and to Dr. Jeanette See of Rio Tinto Alcan, Canada for kindly supplying the red mud sample.

I would also like to extend my thanks to Teresa Gen, the technician of the laboratory of the School of Chemical and Physical Sciences (SCPS) and Sabrina Lange, the technician geochemistry of the School of Geography, Environment and Earth Sciences (SGEES) for their effort and help in allowing me using the TEMA mill. I wish to thanks Dr Olly Pantoja, a research fellow of SCPS and David Flynn, an EMF technician for their guidance and help in handling XRD and SEM instruments.

This project could not have been accomplished without the support of my family members and friends who gave valuable support and encouragement throughout my study. Finally I wish to acknowledge the help given by the group members for learning opportunities they have offered. 


\section{Abstract}

Red mud is the highly alkaline, toxic residue of the aluminium ore bauxite after extraction of the aluminium by the Bayer process. The storage and utilization of red mud present significant environmental problems. The possibility of producing viable inorganic polymers (geopolymers) from red mud and its precursor mineral bauxite was investigated, using sodium hydroxide and/or sodium silicate as the activator, and adjusting the composition of the mixture by the addition of fine silica or $\rho$-alumina. The compressive strengths of the samples were measured after curing for 21 days. Although all the samples showed drying cracking, the strengths were very encouraging, the highest strength being $58 \mathrm{Mpa}$ from a red mud sample containing additional silica, and the highest strength from bauxite samples being $28 \mathrm{MPa}$; the compositions of these samples also being adjusted by the addition of fine silica. These strongest samples were prepared from red mud and bauxite that had been calcined at $500^{\circ} \mathrm{C}$ given by RMGP4, and $28 \mathrm{MPa}$ from BS2. They were made from calcined red mud and bauxite, which therefore seem to be more reactive to alkali than the as-received materials. XRD, SEM/EDS and solid-state NMR spectroscopy were used to study the microstructure and compositions of the end products. XRD revealed that iron occurs as hematite $\left(\mathrm{Fe}_{2} \mathrm{O}_{3}\right)$ in the red mud, bauxite and most of the red mud geopolymers, and is present as other crystalline minerals in the other geopolymer samples. SEM spectroscopy shows that the red mud and bauxite were relatively highly porous and non-crystalline. EDS confirms that iron is present as one of the major elements in the material as well as in the geopolymers. ${ }^{27} \mathrm{Al}$ NMR spectroscopy revealed that $\mathrm{Al}$ is present in more tetrahedrally coordinated sites than in octahedral. ${ }^{29} \mathrm{Si}$ NMR is greatly affected by the presence of iron, resulting in very noisy spectra and in some cases no signals were obtained. These results suggest that iron does not necessarily interfere with geopolymer formation, and 
thus the utilisation of red mud to produce usefully strong geopolymers on a larger scale is feasible, provided the problem of cracking can be solved.

\section{Introduction and literature survey}

This project is aimed primarily at synthesising novel and useful inorganic materials from red mud, the by-product of the Bayer process. During the Bayer process, bauxite ore is refined into alumina which is subsequently electrolytically smelted to produce aluminium. According to the website of the International Aluminium Institute, the world aluminium production increased by around 2,000 million tonnes per year from 2009, reaching almost 50000 million tonnes by the end of 2013 (Figure 1).

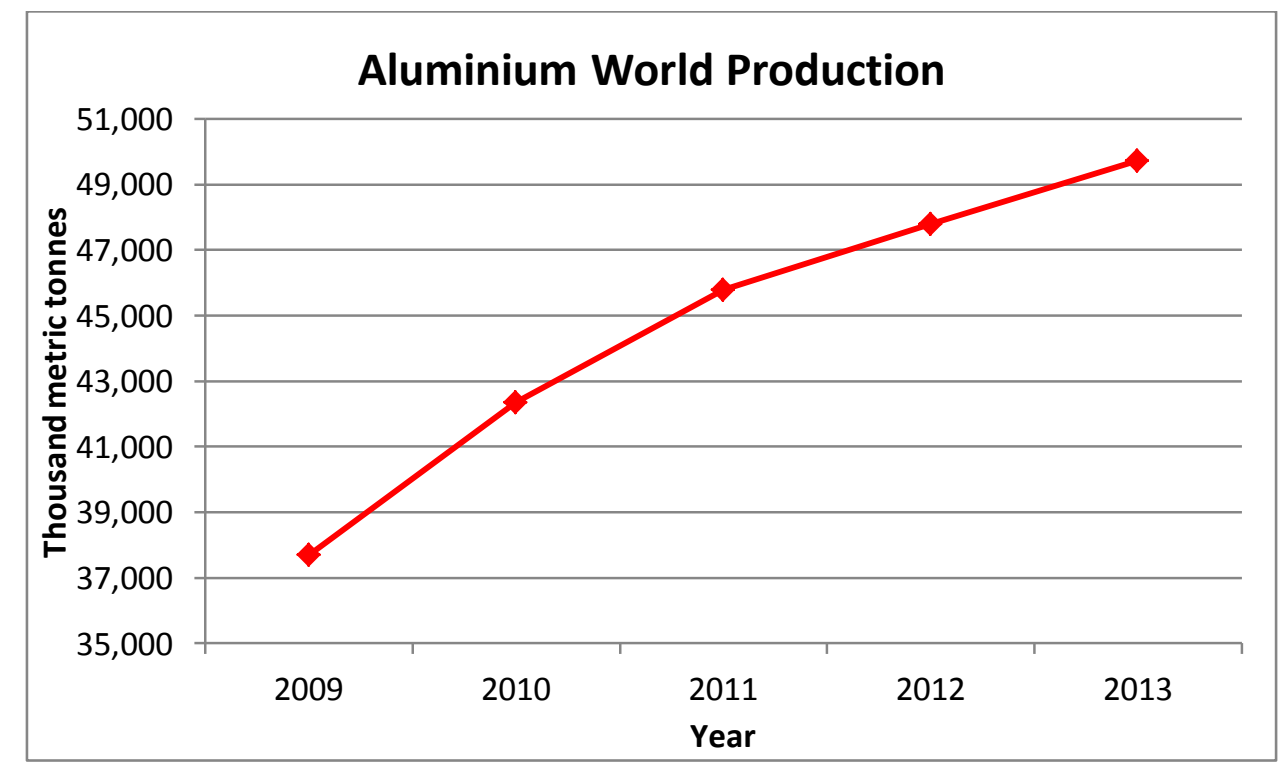

Figure 1: Worldwide aluminium production for the year 2009 - 2013. Data from World Aluminium Website http://www.world-aluminium.org/statistics/\#data. 
This rise in aluminium production is likely to continue for centuries due to its large number of industrial applications in the transport, construction, packaging, electrical and other sectors. Despite being one of the most abundant metals on earth, aluminium was once considered as a precious metal. This is because a huge amount of electrical power is required for the electrochemical smelting of alumina to aluminium by the Hall-Héroult process. As electricity became cheaper and the smelting processes involved were made more efficient, aluminium has now become an inexpensive metal. Figure 2 lists the primary aluminium producing countries as at 2013. China contributes nearly half (44\%) of the world aluminium production, followed by North America (10\%), East and Central Europe (8\%) and the GCC (Gulf Cooperation Council, $8 \%)$.

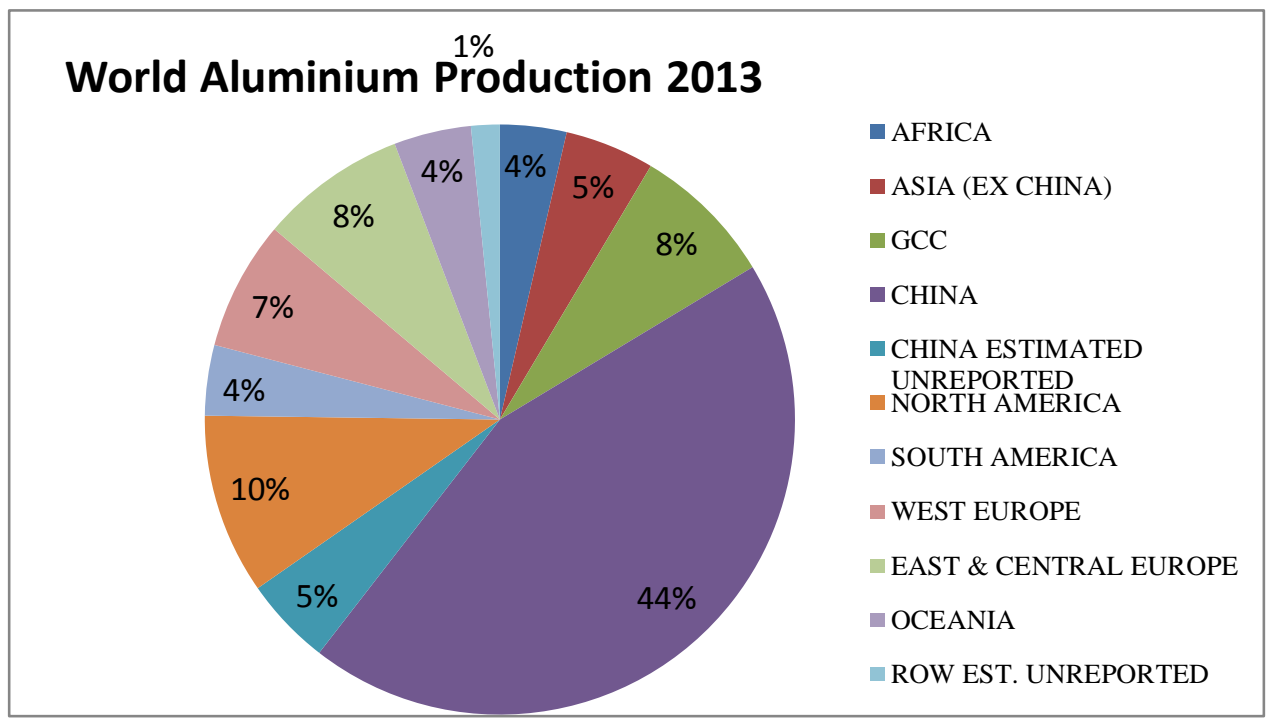

Figure 2: Primary world aluminium production for the year 2013. Data from World Aluminium Website http://www.world-aluminium.org/statistics/\#data

The world total aluminium consumption was 50272 million tonnes in 2013 with China being the main aluminium user (46\%of the total consumption), followed by Asia (20\%) and Europe (14\%), according to the European Aluminium Association [1]. Because the amount of 
aluminium produced has become greater than the amount consumed, the aluminium industry has experienced a surplus that caused its price to drop year after year. The ICRA Management Consulting Services Limited (IMaCS) reported that the price of aluminium declined by $19 \%$ from $\$ 2400$ to $\$ 230$ per tonne in 2011 . In 2012 the price continued to decline to $\$ 2000$ and did not change much in 2013 [2]. This price is unlikely to bounce back as the market surplus is increasing each year. Despite this price drop, the aluminium industry is expected to continue to be a large-scale operation due to the fact that aluminium is the second most widely used metal after iron. In the production of aluminium, the naturally-occurring mineral bauxite (Fig. 3) is converted by the Bayer process into aluminium oxide, which subsequently smelted into aluminium metal by a process called the Hall-Héroult electrolysis process [3].
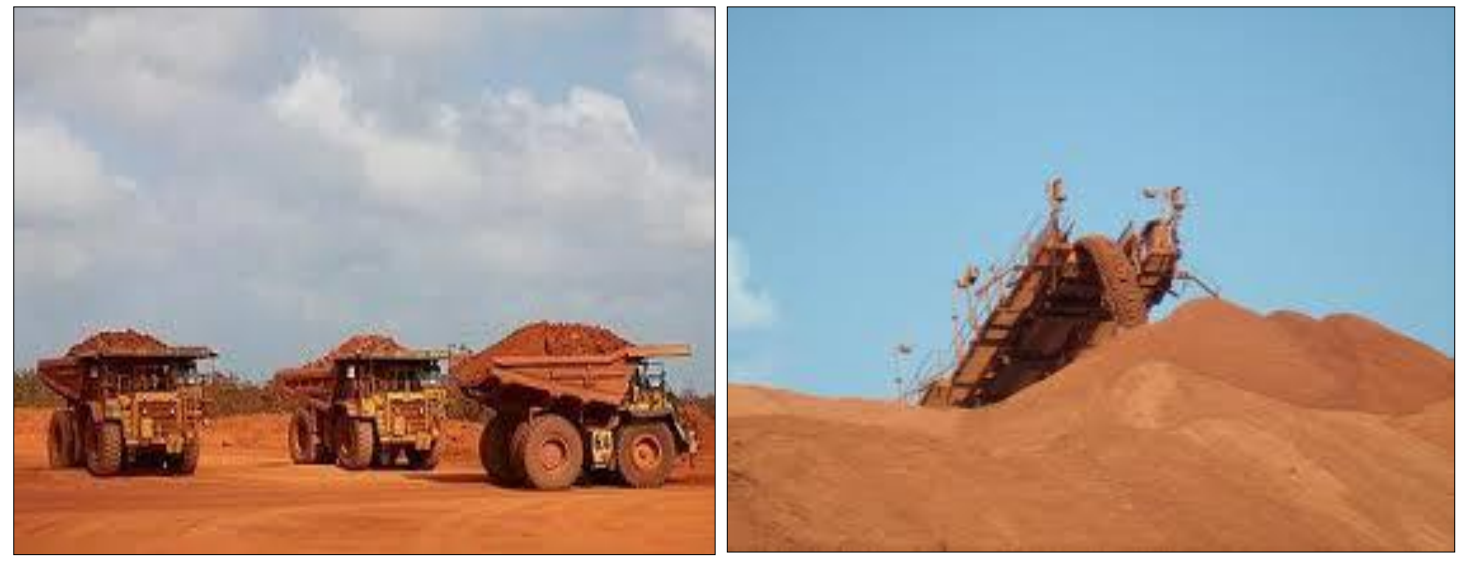

Figure 3: Trucks loaded with bauxite ore for transport to the crusher. From www.riorinto.com.

Bauxite has a typical chemical composition shown in Table 1, and its high aluminium content makes it one of the principal source minerals for aluminium production. The production of 1 tonne of aluminium requires 4.6 tonnes of bauxite (Fig. 4). 


\begin{tabular}{ccccc}
\hline Oxides $(w t \%)$ & $\begin{array}{c}\text { Red mud } \\
\text { raw }\end{array}$ & $\begin{array}{c}\text { Red mud } \\
\text { calcined }\end{array}$ & Bauxite raw & $\begin{array}{c}\text { Bauxite } \\
\text { calcined }\end{array}$ \\
\hline $\mathrm{SiO}_{2}$ & 10.52 & 11.46 & 3.94 & 4.83 \\
$\mathrm{Al}_{2} \mathrm{O}_{3}$ & 22.12 & 24.10 & 49.70 & 60.97 \\
$\mathrm{Fe}_{2} \mathrm{O}_{3}$ & 38.92 & 42.41 & 18.37 & 22.53 \\
$\mathrm{MnO}$ & 0.02 & 0.02 & $<0.01$ & 0.01 \\
$\mathrm{MgO}$ & 0.10 & 0.11 & 0.03 & 0.04 \\
$\mathrm{CaO}$ & 1.36 & 1.48 & 0.03 & 0.04 \\
$\mathrm{Na} 2$ & 6.82 & 7.43 & 0.05 & 0.06 \\
$\mathrm{~K}_{2} \mathrm{O}$ & 0.55 & 0.60 & 0.01 & 0.01 \\
$\mathrm{TiO}_{2}$ & 7.61 & 8.29 & 2.91 & 3.57 \\
$\mathrm{P}_{2} \mathrm{O}_{5}$ & 0.21 & 0.23 & 0.06 & 0.07 \\
$\mathrm{SO}_{3}$ & 0.59 & 0.64 & - & - \\
$\mathrm{LOI}$ & 10.51 & 3.21 & 24.92 & 7.86 \\
\hline
\end{tabular}

Table 1: Chemical composition of materials by XRF analysis.

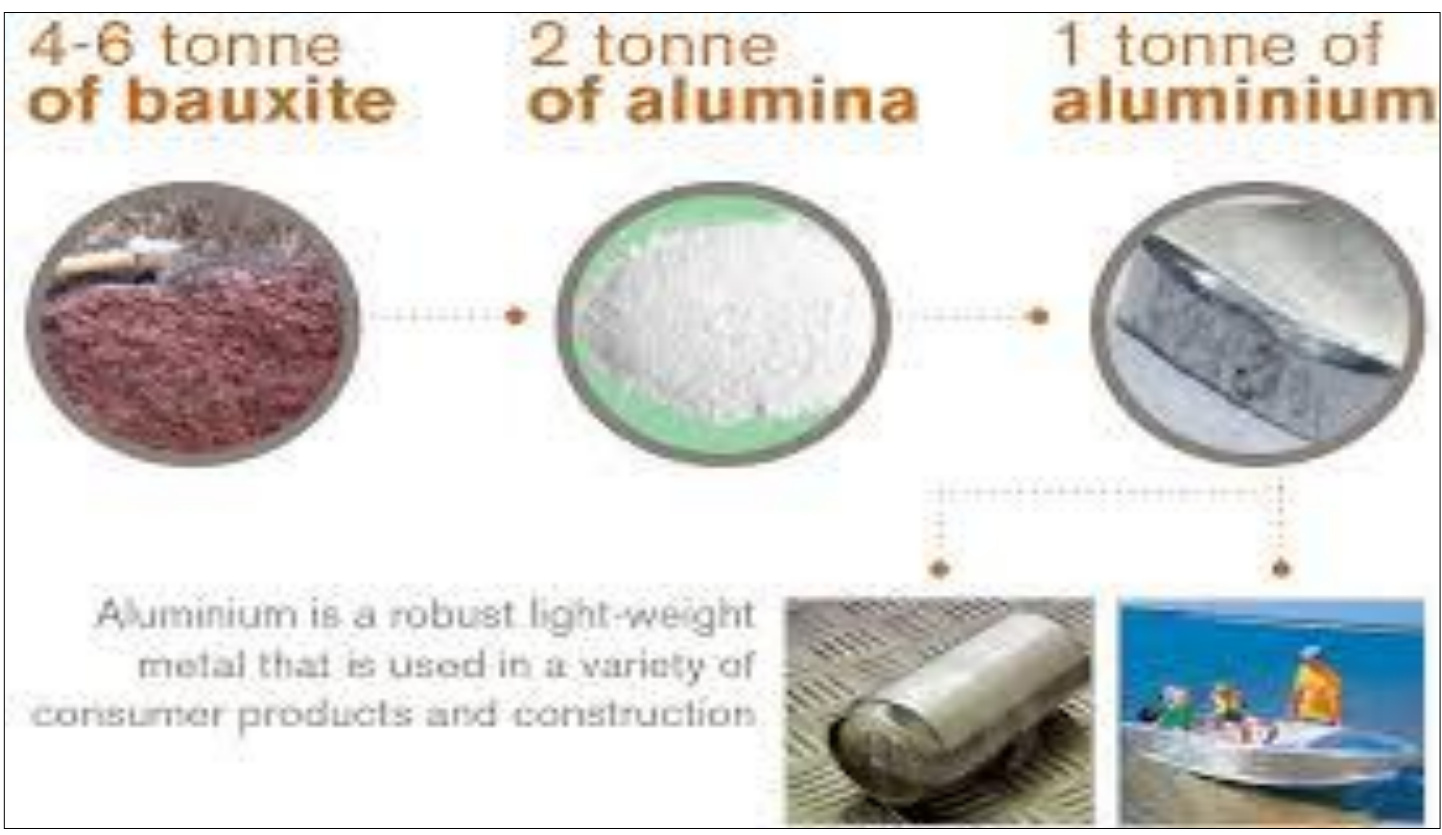

Figure 4: Each 4 tonnes of bauxite produces 2 tonnes of alumina and subsequently 1 tonne of aluminium. As the by-product 2 tonnes of red mud is also generated by the Bayer process.

The Bayer process, shown schematically in Fig. 5, involves leachingthe crushed bauxite ores with hot concentrated solution of sodium hydroxide at high temperature up to $240{ }^{\circ} \mathrm{C}$ and 1 6 atm pressure [3]. During this process, bauxite residue (red mud) is formed as an insoluble waste. Bauxite residue mainly composed of silica $\left(\mathrm{Si}_{2} \mathrm{O}_{3}\right)$, alumina $\left(\mathrm{Al}_{2} \mathrm{O}_{3}\right)$, ferric oxides 
$\left(\mathrm{Fe}_{2} \mathrm{O}_{3}\right)$, calcium oxide $(\mathrm{CaO})$ and sodium oxide $\left(\mathrm{Na}_{2} \mathrm{O}\right)$. It is sometimes referred to as the red mud due to its brick red colour from $\mathrm{Fe}_{2} \mathrm{O}_{3}$. Bauxite residue leaves the process as a highly alkaline slurry with $\mathrm{pH}$ 10-12.5 [4]. This accounts for its high content of sodium hydroxide and calcium. These two components are responsible for the toxicity of red mud. The typical chemical composition of red mud is shown in Table 1. Since aluminium is the second largest metal market in the world, the amounts of bauxite residue produced are also huge. Thus, the issue of red mud toxicity and its disposal has become an increasingly important matter area attracting the attention of researchers.

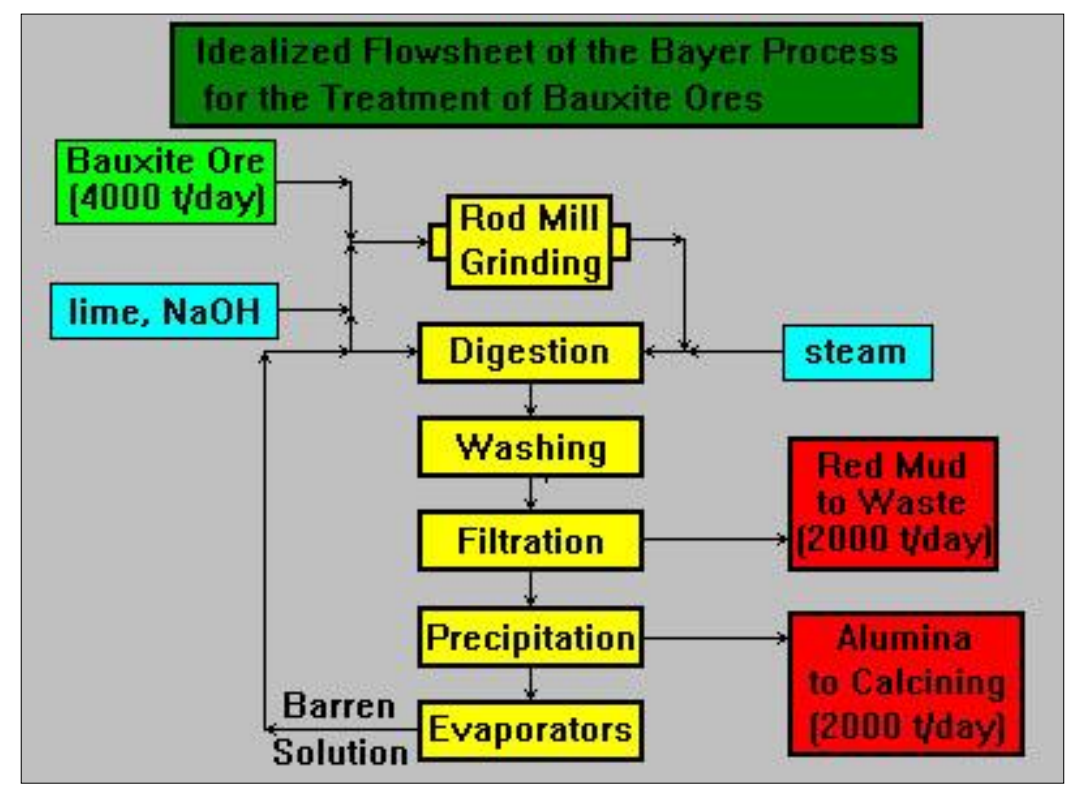

Figure 5: Flowsheet depicting the Bayer Process for producing alumina from bauxite. Picture from http://www.jmeech.mining.ubc.ca/MINE290/proces/Aluminum.php.

\section{Hungary's red mud spill 2010}

The difficulty of safe disposal of bauxite residue (red mud) was brought to world attention by a tragic accident on $4^{\text {th }}$ October $2010[5,6]$. A dam used for bauxite residue storage 
at the Ajkai Timföldgyár alumina plant in Hungary burst and flooded several towns. The amount of red mud released was nearly 1 million $\mathrm{m}^{3}$ and polluted about 1000 acres of land [7]. The caustic red sludge killed ten people including a 3-year old child, and injured more than 120 , chemically burning their skin, and destroyed three villages (Figs. 6,7) [8]. According to the National Disaster Management Directorate, several hundred tons of plaster was poured into the contaminated Marcal River to bind the sludge and prevent it from flowing downriver towards the Danube, Europe's second longest river. Unfortunately three days later, the caustic sludge reached the river Danube and its tributary, the Raba. Although dead fish were found in both rivers, the toxic levels in both rivers were said to be safe for humans.

A year later, the affected areas had been bulldozed and compensation, including houses was given to the red sludge victims. The damage from this spill cost Hungary more than 111 million euros for the reconstruction and building of new homes [9]. The company that caused the toxic red mud spill, MAL Hungarian Aluminium was fined 472 million euros for environmental damage and infringement of waste management regulations [10]. This catastrophe was one of Europe's worst environmental disasters for the last 20 to 30 years, and illustrates the pressing need for continued research into remediation of this toxic waste product, by safer storage methods, or its conversion into useful products. 

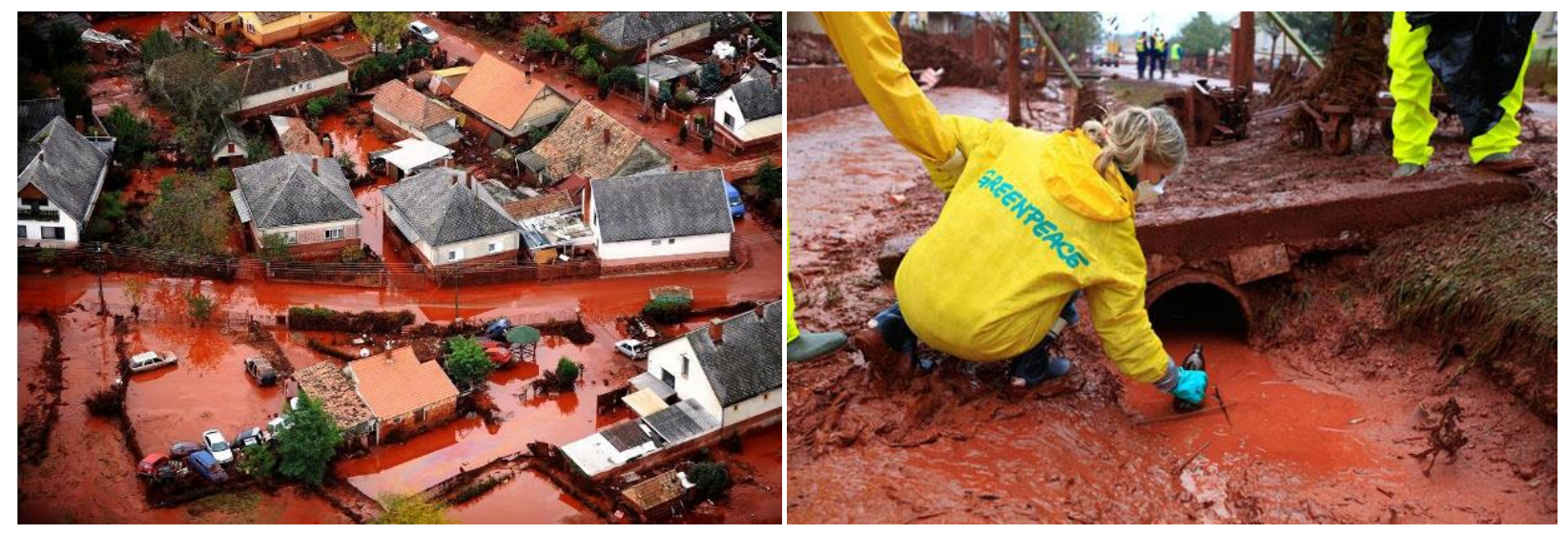

Figure 6: View from the top of village area covered by toxic red mud (left). A Greenpeace activist takes a sample of the toxic mud in nearby town for analysis (right). Picture from http://www.surgeforwater.org/water/2010/10 and

http://news.xinhuanet.com/english2010/world/2010-10/06/c 13543861.htm. 


\section{Problems with red mud}

Rapid production of aluminium produces red mud that reached 3 million tonnes at the end of 2010 and the number is estimated to increase at a steady rate of 120 million tonnes per annum [11]. As a result, red mud is among the largest industrial wastes that strictly need attention especially in storage practices. Power et al. [11] reviewed about bauxite residue issues in four series of reports in details. Since Bayer plant was patented in 1888 by Karl Josef Bayer, there are several ways of bauxite residue disposal methods. Starting with marine discharge and lagooning in 1970's two other methods were developed which were the "dry" stacking and the dry cake disposal methods. Of the four methods, lagooning is the simplest and the lowest cost land-based disposal method. This method has been used by two thirds of aluminium refineries in 1965. The tragic Ajkai Timföldgyár alumina refinery also used lagooning methods to store their bauxite residues, in which the reason behind their wall collapse was due to low solid content (Fig. 7).

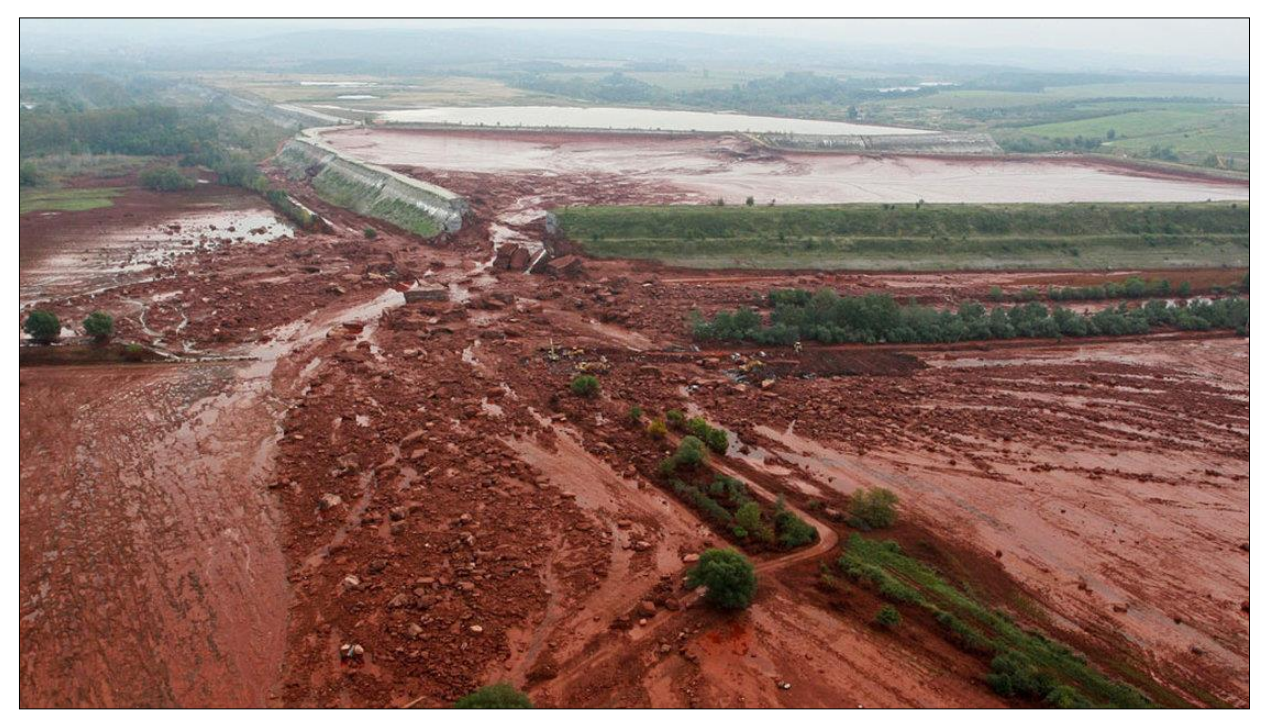

Figure 7: The broken corner of Ajkai Timföldgyár plant reservoir, top centre releasing approximately one million cubic meters of red mud liquids. Photo from http://www.npr.org. 
The continued production of millions of tons of red mud every year demands increased research into storage practices so as to minimize the environmental hazard. Current technologies offer some possibilities such as the use of wet and dry stocking [12], mixed stocking [4], and coagulant for wastewater treatment [13], one of which is to convert the alkaline waste into a potentially available resource for the production of other products. Since red mud was first produced, much research has been carried out to investigate other potential applications. Up until 2008, $59 \%$ of the total patents for bauxite residue (red mud) utilization was filed under the category "construction and chemical applications", of which $81 \%$ were for civil engineering and building construction. These patents are for cements, aggregates, bricks and blocks, geopolymers and remediation of radioactive wastes [14].

Previous attempts to utilize red mud as a construction material have been confined to alkali-activated composites of red mud with other waste materials. Thus, red mud has been combined in varying proportions with electric arc slag [15], fly ash [16-19], metakaolin [3, 20, 21], rice husk ash [22], granulated ground blast furnace slag (GGBS) [23] and Portland cement [24]. The compressive strengths of the resulting materials are extremely variable, ranging from 5.5 to $49.2 \mathrm{MPa}$, but most in the range of 5-20 MPa. To our knowledge, no previous attempts have been made to produce geopolymers from red mud or its parent bauxite alone, and the present work represents the first such study. 


\section{Geopolymerisation}

In 1970's a French materials scientist Joseph Davidovits applied the term "geopolymer" to the newly discovered inorganic material that now is largely used in many industrial applications. Geopolymers are X-ray amorphous ceramic-like aluminosilicate materials that harden at ambient temperature. Conventional methods of geopolymerisation involve three main steps, dissolution of aluminosilicate oxide in alkali solution, followed by transportation of dissolved $\mathrm{Al}$ and $\mathrm{Si}$, and lastly, polymerisation of these species. These three steps were discussed in a recent publication involving the geopolymerisation of metakaolinite [11], shown schematically in Figure 8.

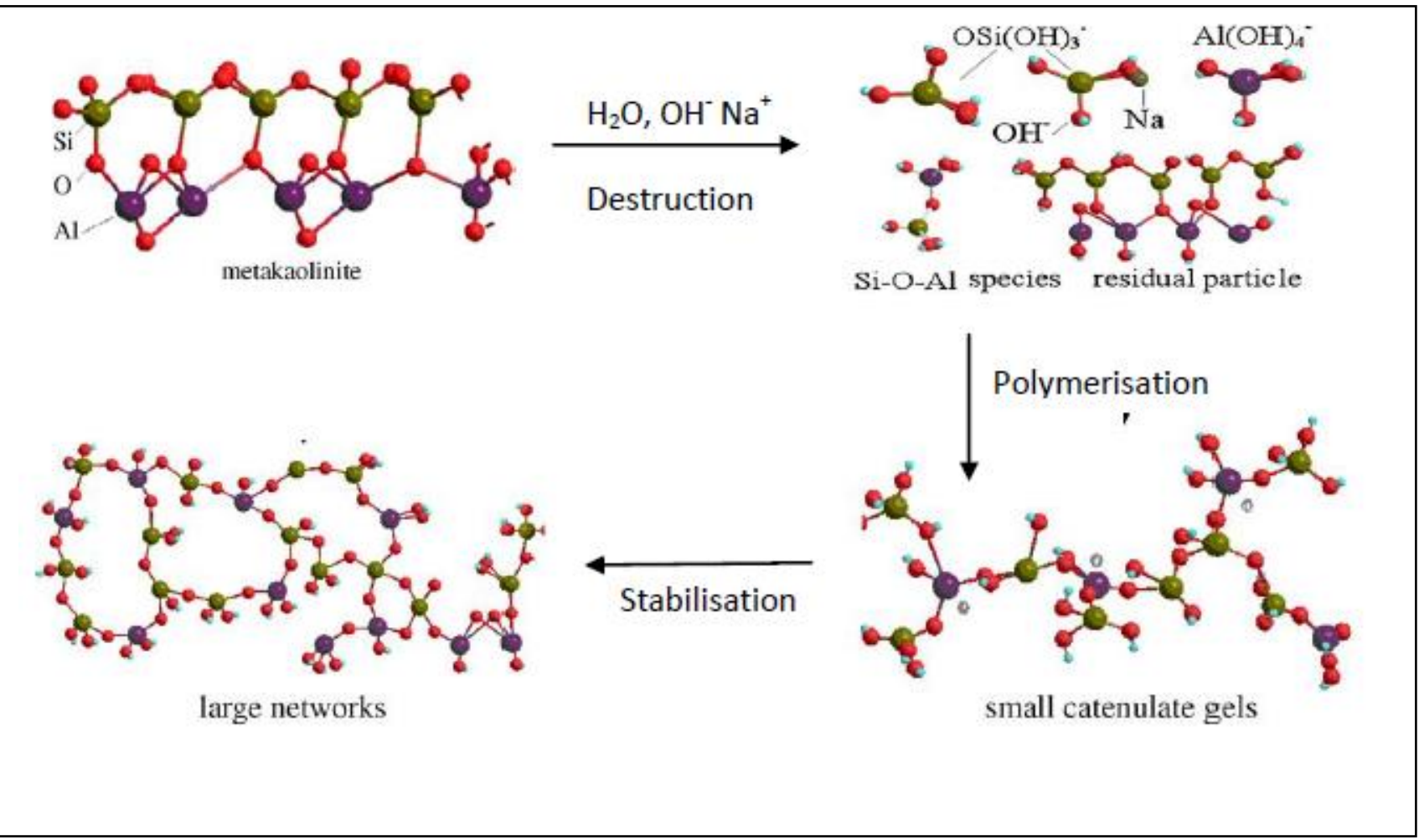

Figure 8: The destruction, polymerisation and stabilisation steps in geopolymerisation of metakaolinite [25]. 
During the destruction step, amorphous phases such as aluminosilicates are broken down by alkali activation to produce the small reactive aluminate $\left(\mathrm{AlO}_{4}\right)$ and silicate $\left(\mathrm{SiO}_{4}\right)$ species. Exothermic attack of $\mathrm{OH}^{-}$anions on the oxides produce alumina and silica oligomers such as $\mathrm{OSi}(\mathrm{OH})^{3-}$ and $\mathrm{Al}(\mathrm{OH})^{4-}$ which then condense into monomers. As the number of monomers increases, they polymerise into gels and eventually form the large random geopolymer network [25].

\section{Geopolymers as substitutes for Ordinary Portland Cement (OPC)}

The study of geopolymers has increased very rapidly over the last 30 years. Many aluminosilicate raw materials have been shown to produce geopolymers with useful properties, especially industrial wastes such as fly ash [26], pozzolans [27], metakaolin [28], blast furnace slag [29] and mixtures of these with red mud [16]. The use of industrial by products as the source materials for geopolymer not only reduces the costs significantly but also has the environmental advantage of mitigating environmental pollution to a large extent [30] and removing the need for setting aside huge areas of land to store wastes. In recycling industrial wastes, the best option is to look for applications that involve the largest possible volume of the waste. A potential bulk use of these wastes is as building materials, e.g. cements, bricks, concrete and ceramics.

To serve as building materials any new synthetic inorganic material must meet the requirements needed for construction. Conventional geopolymer shows outstanding technical properties such as high resistance to corrosion and fire, high compressive and tensile strength, capable of lasting hundreds of years and low shrinkage [31, 32]. Apart from the possibility that geopolymers may have been used in ancient Egyptian buildings [33], geopolymers have not been 
used for construction purposes long enough to prove their lifespan, but all their other properties indicate them to be an excellent substitute for Ordinary Portland Cement (OPC), the basic ingredient of concrete that acts as a binder to reinforce the concrete. Since concrete is the second most consumed substance after water, the demand for concrete as a construction material, and therefore OPC is very high. The manufacture of 1 tonne of OPC emits an almost equivalent amount of carbon dioxide $\left(\mathrm{CO}_{2}\right)$, with an average of $222 \mathrm{~kg} \mathrm{CO}_{2}$ emitted per ton of cement produced [34]. Today, worldwide cement production is two billion tonnes of cement per year, releasing two billion tonnes of $\mathrm{CO}_{2}$ to the environment; this contributes up to $7 \%$ of the earth's total $\mathrm{CO}_{2}$ emission. Such figures will increase very quickly if no action is taken to mitigate the production of $\mathrm{CO}_{2}$, which is a major greenhouse gas threatening the world's climate and causing environmental pollution. Geopolymers are potential alternative construction materials for replacing $\mathrm{OPC}$ and hence reducing the emission of $\mathrm{CO}_{2}$, since their production involves the emission of considerably less $\mathrm{CO}_{2}$ than OPC.

\section{Factors influencing geopolymer formation from red mud and red mud mixtures}

Several main parameters have been identified in the synthesis of inorganic polymers. These are: the concentration and type of the alkaline activator, the solid/liquid ratio, the $\mathrm{SiO}_{2} / \mathrm{Al}_{2} \mathrm{O}_{3}$ ratio, the curing conditions and curing time. 


\section{Effect of concentration of alkali activator}

The most common activator used in geopolymer synthesis is a mixture of sodium silicate and sodium hydroxide, $\mathrm{NaOH}$. Other alkalis may also be used, for example the combination of potassium silicate and potassium hydroxide, $\mathrm{KOH}$ [35]. Sometimes a small amount of water is added to assist the mixing, but it is important to prepare a concentrated alkali activator liquid otherwise the end product would be a crystalline zeolite rather than a geopolymer [36]. Giannopoulou et al. [37] have discussed how the concentration of $\mathrm{NaOH}$ changes the compressive strength of inorganic polymeric materials. Their results show that the compressive strength of red mud/metakaolin-based materials increased with increasing $\mathrm{NaOH}$ concentration up to $8 \mathrm{M}$, after which the strength decreased again. Similarly, the strength of ferronickel slagbased materials showed increased compressive strength up to $7 \mathrm{M} \mathrm{NaOH}$ concentration and then decreased. Generally the strengths of inorganic polymers increase as the $\mathrm{NaOH}$ concentration increases. This is because the extra amount of $\mathrm{NaOH}$ in the activator accelerates the dissolution process. Thus, $\mathrm{Si}^{4+}$ and $\mathrm{Al}^{3+}$ ion from amorphous phase are dissolved much faster, hence enhancing the geopolymerization process.

Dimas, Giannopolou et al. [38] designed a study to use red mud as the raw material for the formation of a geopolymer primarily for use in the construction sector as massive bricks. They managed to synthesis inorganic materials with quite high compressive strength (20.4 MPa), very low water absorption $(1.28 \%)$ and excellent fire resistance due to thermally stable at extremely high temperature $\left(400-1000{ }^{\circ} \mathrm{C}\right)$. Hence they concluded that the red mud-derived geopolymer was a promising building material. 
He, Zhang et al. [16] have reported an investigation on the effect of the source materials on the microstructure and mechanical properties of geopolymers. They compared two geopolymers synthesised from a metakaolin-red mud-fly ash mixture. Note that metakaolin is not a waste material, but red mud and fly-ash are industrial wastes. Unconfined compression testing of the geopolymer derived from metakaolin exhibited higher compressive strength (31 MPa) than the red mud-fly ash mixture (13 MPa). This was explained in terms of the concentration of alkali used in the synthesis, and the quantity, characteristics and reactivity of starting materials.

As reported by Hardjito, Wallah et al. [39], alkalinity is the most important factor in geopolymerisation. In their work they added to metakaolin 6.5-7.8 $\mathrm{M} \mathrm{NaOH}$ solution with a $\mathrm{pH}$ greater than 14 . On the other hand, no $\mathrm{NaOH}$ solution was added to the red mud-fly ash mixture, since its $\mathrm{pH}$ was 11.9 due to the residual $\mathrm{NaOH}$ present in the bauxite waste. The higher concentration of alkali activated and dissolved the amorphous silica and alumina faster and hence produced more reactive precursors. This resulted in the formation of more geopolymeric binder that increased the stiffness and compressive strength of the final geopolymer. More reactive starting materials also improve the geopolymer strength. The calcination step breaks down most crystalline phases making them amorphous and more reactive. In that study[39], the metakaolin and fly ash were calcined but the red mud was not. With greater alkalinity, the calcined metakaolin geopolymer showed greater compressive strength than the red mud-fly ash geopolymer. 


\section{Solid/liquid ratio}

The solid-to-liquid ratio is very important in geopolymer synthesis. This ratio (or vice versa) is the key whether or not the geopolymer paste is workable. The presence of more water is required to produce a paste with good consistency that will help during casting. However, water has its own important role in geopolymer synthesis. The water content determines the solid/liquid ratio of the uncured geopolymer paste. The amount of water should be just enough to produce concentrated pastes in order to yield geopolymers with good compressive strength.

Panias, Giannopoulou et al. [40] have examined the effect of different water contents in relation to the compressive strength and report that the compressive strengths of geopolymers increase exponentially as the solid/liquid ratio increases. However, this relationship was found to change when the compressive strength dropped significantly from $24.54 \mathrm{MPa}$ at a solid/liquid ratio of 2.05 to $4.67 \mathrm{MPa}$ at a solid/liquid ratio of 2.12. Even though the lower amount of water should give a better compressive strength, too low water content caused insufficient wetting and the geopolymer paste was not workable; thus, the compressive strength was affected negatively.

Zuhua, Xiao at al. [36] have discussed the role of water in the synthesis of calcined kaolin-based geopolymers. They divided the geopolymerization sequence into period I (the first 1000 min of reaction) and period II (after 1000 min of reaction). During period I the higher liquid/solid ratio resulted in a faster reaction rate due to the water being involved in the dissolution step, where water from the alkali activator helps to separate the aluminosilicate materials into $\mathrm{Al}-\mathrm{O}$ and $\mathrm{Si}-\mathrm{O}$ units. After this step the reaction mechanism may change from consuming water to producing water (period II). During this period, systems with a lower liquid/solid ratio will react faster because the presence of the extra water will inhibit the 
condensation reaction. In this study, the liquid/solid ratios of $1.00,1.20$ and 1.25 were tested, but the compressive strengths of the corresponding geopolymers were not measured.

In another study, Joshi and Kadu [26] reviewed the effect of the liquid/solid ratio on the compressive strength. They varied the ratio from 0.10 to 0.50 but only the ratios $0.25,0.30,0.35$ and 0.40 are workable. Of those ratios, the highest compressive strength observed was about 13 $\mathrm{MPa}$, which was given by the ratio 0.35 . For the lower ratios, more water was needed to prepare the samples, which leads to lower compressive strengths.

Giannopoulou, Dimas et al. [37] also investigated the effect of the ratio but reported it as the ratio of solid/liquid. The compressive strength of geopolymers they studied increased linearly as the solid/liquid ratio was increased. In that study, the compressive strength of red $\mathrm{mud} / \mathrm{metakaolin}$ geopolymers with solid/liquid ratios of 2 to 3 increased from 3.8 to $9.5 \mathrm{MPa}$. By measuring the geopolymer apparent density and porosity, they concluded that higher solid/liquid ratios resulted in higher compressive strengths due to the presence of more undissolved solid particles and more geopolymeric binder per volume of product which contributes positively to the strength of the geopolymer. 


\section{Geopolymers from materials with high Fe content}

With the aim of producing inorganic polymer form bauxite residue one has to consider the presence of ferric oxide $\mathrm{Fe}_{2} \mathrm{O}_{3}$ in the waste. This may affect the kinetics and overall chemistry of geopolymer formation, and even the compressive strength. Perera, Cashion et al. [41] studied the incorporation of Fe into metakaolin-based geopolymer with a Si/Al molar ratio of about 2. Fe was introduced by the addition of freshly prepared ferric (oxy)hydroxide into the metakaolin-based geopolymer. The resulting geopolymer studied using Mössbauer spectroscopy, near-edge X-ray spectroscopy, X-ray diffraction and electron microscopy. These authors concluded that $\mathrm{Fe}$ occupies octahedral sites either as isolated ions or oxyhydroxide aggregates which meant it had not reacted with the geopolymer starting material. However they did not measure the strength of the geopolymer.

Another study was carried out by Bell and Kriven [42] who reported the synthesis of geopolymers using the conventional method of adding synthetic $\mathrm{Fe}_{2} \mathrm{O}_{3} \cdot 2 \mathrm{SiO}_{2}$ powder to potassium silicate solution to produce $\mathrm{K}_{2} \mathrm{O} \cdot \mathrm{Fe}_{2} \mathrm{O}_{3} \cdot 4 \mathrm{SiO}_{2} \cdot 13 \mathrm{H}_{2} \mathrm{O}$ which was an iron-based geopolymer analogue of $\mathrm{K}_{2} \mathrm{O} \cdot \mathrm{Al}_{2} \mathrm{O}_{3} \cdot 4 \mathrm{SiO}_{2} \cdot 13 \mathrm{H}_{2} \mathrm{O}$. The resulting material was soluble in water and was rubbery, hence requiring nearly one year to hardened. This geopolymer consisted of a tetrahedral aluminosilicate network, while the iron was in octahedral coordination. From their analysis they concluded that the desired iron-based geopolymer analogue was not formed, mainly due to the lesser reactivity of the iron silicate powder starting material.

Onisei, Pontikes et al. [43] reported the synthesis of an inorganic polymer from fly ash, lead slag and mixtures of the two. The inorganic polymers made from lead slag contained more than 50 wt. \% $\mathrm{PbO}$ with high $\mathrm{Fe}, \mathrm{Si}$ and $\mathrm{Zn}$ content, and a high average $\mathrm{Si} / \mathrm{Al}$ ratio of 33. To 
increase the $\mathrm{Al}$ content, they added fly ash to the lead slag inorganic polymer up to $80 \%$ by volume and the $\mathrm{Si} / \mathrm{Al}$ ratio dropped to 5 . The maximum compressive strength obtained was 48 $\mathrm{MPa}$, which was obtained from the inorganic polymer made from a mixture of $30 \mathrm{wt}$. \% fly ash and 70 wt. \% lead slag. The SEM image of this inorganic polymer showed iron resides in distinct areas as iron oxides and metallic iron, both in association with spinels and in the amorphous phase.

Pontikes, Machiels at al. [44] studied the microstructure of geopolymer materials made from slag resulting from different cooling rates for a material of specific $\mathrm{Al} / \mathrm{Fe}$ ratio. The slag was produced using a plasma reactor, and then cooled in four different ways. Samples of inorganic polymers were made by mixing the slag with alkali activator made from $50 \mathrm{wt} . \% 10 \mathrm{M}$ $\mathrm{NaOH}$ and 50 wt. \% sodium silicate solution. When ready, the solution was poured into square plastic moulds, sealed and cured at ambient conditions for 28 days and their compressive strengths were measured. Different slag cooling methods gave different strengths. The lowest compressive strength of less than $5 \mathrm{MPa}$ were given by the samples prepared from slag cooled by the "slag pot" method, while the slag cooled using the "layer" method showed higher strengths in the range of 10-15 MPa. The highest strength, recorded by a slag cooled by the "water quenching" method, had a value of $60 \mathrm{MPa}$. It was believed that the presence of iron in the inorganic polymer increased the setting time of the polymer, because higher compressive strengths were obtained for samples cured for more than 90 days.

Recently Lemougna, MacKenzie et al. [45] investigated the behaviour and role of iron in the formation of geopoymers from volcanic ashes. The ashes were collected from two different regions of Cameroon, the west and the littoral. Both ashes produced geopolymers showing excellent compressive strengths, as high as $60 \mathrm{MPa}$ (west ash) and $33 \mathrm{MPa}$ (littoral ash). Using 
Mössbauer spectroscopy they identified ferrous and ferric sites in the volcanic ashes in which the iron was present in the crystalline minerals ferroan forsterite and augite. Upon activation with $\mathrm{NaOH}$, a large portion of augite minerals reacted in such a way that distorted tetrahedral iron sites were formed. This suggested that iron is involved in structural network formation and may not negatively affect the compressive strength.

\section{Objectives of the present work}

Much of the previous research is focussed on bauxite residue (red mud) disposal methods, its influence on the environment and possible applications for bauxite residue. These studies have concentrated mainly on diluting the red mud with other waste or non-waste materials to produce viable alkali-activated materials of sufficient strength to be considered as construction materials. By contrast, the present research is aimed at exploiting geopolymer chemistry to convert red mud into solid products that may be safely stored, or used as construction materials, preferably without the need to introduce other materials to develop strength. It was recognized that the chemical composition of the red mud was such that its composition may have to be adjusted by the addition of silica or alumina sources, but the addition of these was deliberately kept to a minimum, and their effect on the geopolymerization chemistry was studied by XRD, solid-state ${ }^{27} \mathrm{Al}$ and ${ }^{29}$ Si MAS NMR spectroscopy and scanning electron microscopy. The compressive strengths of the products were also measured, since this property is of primary importance for construction materials. In another part of this project it was also of interest to compare the behavior of the parent bauxite as a starting material for geopolymer synthesis. 


\section{Materials and methods}

\section{Materials}

A high- $\mathrm{Fe}_{2} \mathrm{O}_{3}$ red mud (source: Rio Tinto Alcan, Canada) and bauxite (Weipa, Far North Queensland) were used as the raw materials in this study. The as-received raw material, particularly the bauxite, was in the form of hard lumps (Fig. 9) which were ground to pass a105 $\mu \mathrm{m}$ mesh sieve, using a vibratory mill (Bleuler, Switzerland) with a tungsten carbide pot and grinding rings. The red mud was supplied in a partially dried form, having had $46 \%$ of its original water previously removed for safer transportation.

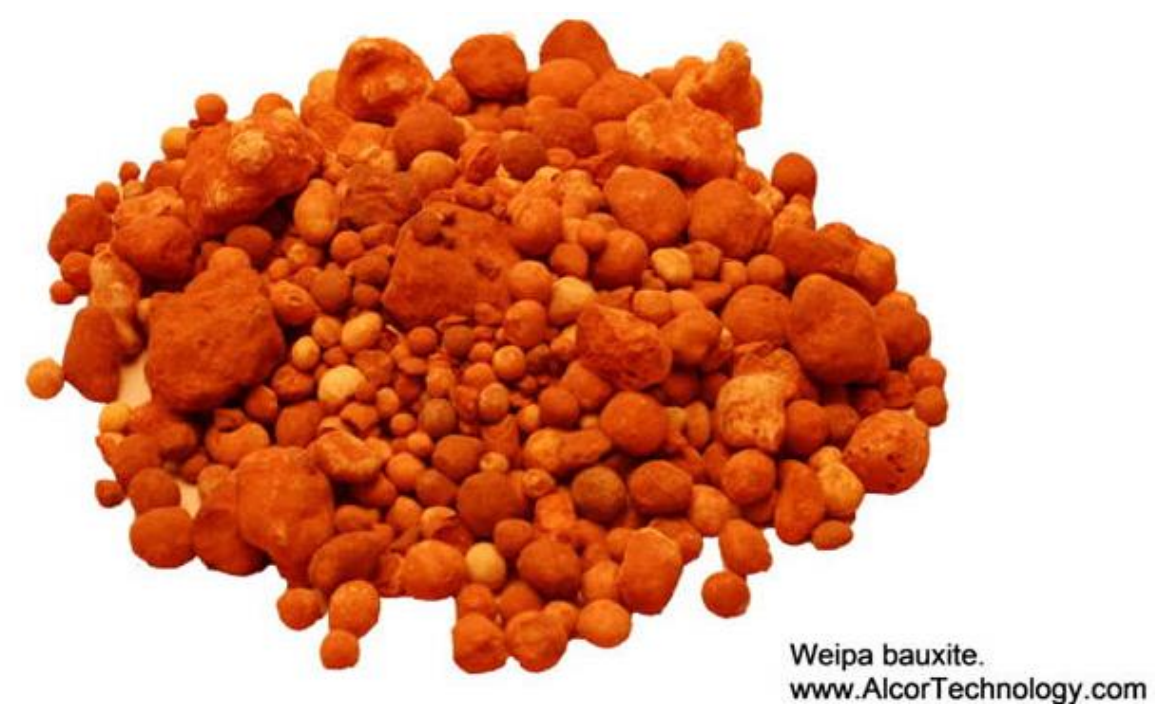

Figure 9: As-received Weipa bauxite.

The alkaline activator used was a mixture of $\mathrm{NaOH}$, sodium silicate solution (FERNZ Chemical Co, NZ, Type "D”, $\mathrm{Na}_{2} \mathrm{O} / \mathrm{SiO}_{2}=0.48$, solids content $=41.1$ mass $\left.\%\right)$ and water. Silica fume (Elkem 971-U, Elkem, Norway) and $\rho$-alumina (Alphabond 300, Almatis Gmbh, Germany) was used as the source of $\mathrm{Si}$ and $\mathrm{Al}$ to adjust the compositions of the samples. A number of possible geopolymer recipes were designed to achieve molar ratios known to be important to 
produce viable and workable geopolymers, namely, $\mathrm{SiO}_{2}: \mathrm{Al}_{2} \mathrm{O}_{3}$ about $3, \mathrm{Na}_{2} \mathrm{O}: \mathrm{SiO}_{2}$ about 0.3 and $\mathrm{H}_{2} \mathrm{O}: \mathrm{Na}_{2} \mathrm{O}$ about 10 [46].

\section{Sample preparation}

Geopolymer pastes of different compositions were prepared by mixing the raw materials (ground red mud and bauxite) with the alkaline activator. The water and sodium hydroxide pellets were mixed in a plastic jar, and the resulting mixture was allowed to cool before the addition of sodium silicate "D" solution. Finally red mud or bauxite powder and silica fume were added gradually into the mixture. Details of the proportions of the ingredients and the important molar ratios of the mixtures are shown in Table 2 and 3 respectively. Stirring was done manually using a plastic spatula. The resulting geopolymer pastes were cast into 30 x 30 x $30 \mathrm{~mm}$ moulds (Fig. 10) and were vibrated to release trapped air bubbles. Then the samples were cured in a sealed plastic bag at $60{ }^{\circ} \mathrm{C}$. After 24 hours the bag was removed and samples were left at $60{ }^{\circ} \mathrm{C}$ for further curing. After 21 days the compressive strengths were measured as below. The broken samples were collected for characterization.

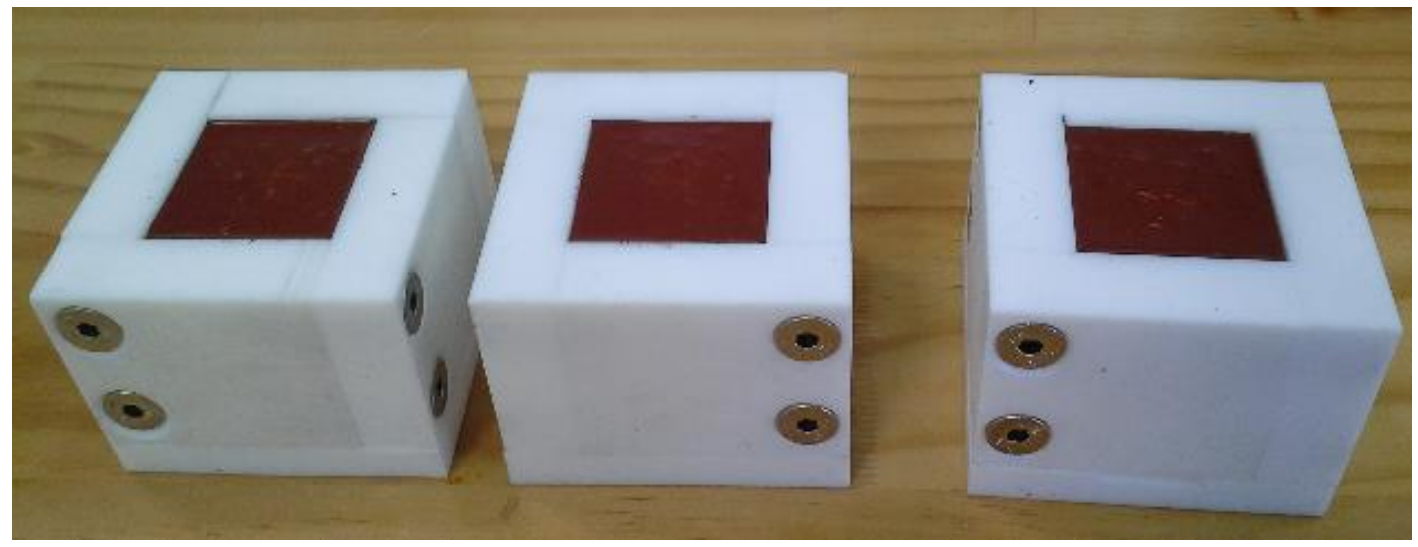

Figure 10: The $30 \mathrm{~mm}^{3}$ polyethene moulds used for the project. 


\begin{tabular}{cccccccc}
\hline Sample & \multicolumn{2}{c}{ Types\& mass (g) } & $\begin{array}{c}\mathrm{NaOH} \\
\text { pellet }(\mathrm{g})\end{array}$ & $\begin{array}{c}\text { Sodium } \\
\text { silicate } \\
\text { "D" }(\mathrm{g})\end{array}$ & $\begin{array}{c}\mathrm{SiO}_{2} \\
\text { fume }(\mathrm{g})\end{array}$ & $\begin{array}{c}\text { Distilled } \\
\text { water }(\mathrm{g})\end{array}$ & $\begin{array}{c}\text { Alphabond } \\
(\mathrm{g})\end{array}$ \\
\hline RMS1 & Raw & 70.01 & 3.50 & 77.00 & 19.26 & - & 22.40 \\
RMS2 & Calcined & 61.97 & 3.10 & 78.12 & 29.15 & 2.41 & 18.61 \\
RMS3 & Raw & 104.02 & - & 33.70 & 6.68 & 18.07 & - \\
RMS4 & Calcined & 99.99 & - & 38.00 & 20.00 & 19.99 & - \\
RMS5 & Raw & 103.95 & 7.44 & - & 16.71 & 50.43 & - \\
RMS6 & Calcined & 85.86 & 7.26 & - & 25.77 & 56.04 & - \\
\hline BS1 & Raw & 61.98 & 7.44 & 76.25 & 29.45 & - & - \\
BS2 & Calcined & 55.10 & 9.35 & 76.18 & 34.15 & - & - \\
BS3* & Raw & 70.60 & - & 49.42 & - & - & - \\
BS4** & Calcined & 33.03 & - & 25.09 & - & - & - \\
BS5 & Raw & 59.95 & 20.4 & - & 50.31 & 47.94 & - \\
\hline
\end{tabular}

*Did not set in 24 hours $* *$ Cracked prior to strength testing

Table 2: Detailed compositions of geopolymer samples.

\begin{tabular}{cccc}
\hline Sample & $\mathrm{SiO}_{2}: \mathrm{Al}_{2} \mathrm{O}_{3}$ & $\mathrm{Na}_{2} \mathrm{O}: \mathrm{SiO}_{2}$ & $\mathrm{H}_{2} \mathrm{O}: \mathrm{Na}_{2} \mathrm{O}$ \\
\hline RMS1 & 2.99 & 0.30 & 9.31 \\
RMS2 & 3.00 & 0.30 & 9.03 \\
RMS3 & 3.00 & 0.30 & 13.74 \\
RMS4 & 3.01 & 0.30 & 11.81 \\
RMS5 & 3.01 & 0.32 & 16.46 \\
RMS6 & 2.93 & 0.33 & 16.87 \\
\hline BS1 & 3.00 & 0.30 & 11.84 \\
BS2 & 3.00 & 0.30 & 8.82 \\
BS3 & 0.84 & 0.41 & 21.45 \\
BS4 & 0.76 & 0.40 & 15.56 \\
BS5 & 3.01 & 0.29 & 13.67
\end{tabular}

Table 3: Molar compositions of the geopolymer samples.

All of these samples were used for compressive strength measurements, but only samples that gave highest compressive strength were selected for SEM, solid-state NMR spectroscopy. 


\section{Sample characterization}

The as-received materials were analysed using XRF, X-ray diffraction (XRD) and thermal analysis (thermogravimetry/differential scanning calorimetry, (TGA-DSC). The crystalline phases in the broken geopolymer samples were characterized using XRD, scanning electron microscopy (SEM), Mössbauer spectroscopy and solid-state nuclear magnetic resonance spectroscopy (NMR).

i. Thermal analysis of raw materials

The red mud and bauxite were analysed by DCS-TGA. Approximately $0.1 \mathrm{~g}$ of sample was heated at a rate of $10{ }^{\circ} \mathrm{C} / \mathrm{min}$ to $500{ }^{\circ} \mathrm{C}$ in flowing air(10 mL/min)using an SDT Model Q600 thermal analyser.

ii. $\quad$ X-ray diffraction (XRD)

Powder XRD patterns were obtained using X'Pert PRO PANalytical with $\mathrm{Cu} \mathrm{K} \alpha$ radiation, operated at $45 \mathrm{kV}$ and $40 \mathrm{~mA}$. The diffraction patterns were collected in the $2 \theta$ range of 10 $80^{\circ}$ at a scan speed of $0.04^{\circ} / \mathrm{s}$ and stepsize of $0.02^{\circ}$. The crystalline phases of the geopolymer samples were determined quantitatively using X'Pert High Score software.

\section{iii. Scanning electron microscopy (SEM)}

SEM images were taken from JEOL 6610LV equipped with energy-dispersive spectroscopy (EDS). Ground samples were mounted on specimen stubs with double sided carbon tape. The samples were coated with a layer of carbon using Q150T Turbo-Pumped Sputter Coater and were kept in a vacuum system prior to SEM imaging. Backscattered electron images of microstructures were taken at 2000 and 10000 times magnifications under high vacuum with 
acceleration voltage of $15 \mathrm{kV}$ and working distance of $10 \mathrm{~mm}$. EDS spot analyses were carried out at the same acceleration voltage and working distance.

iv. Solid state nuclear magnetic resonance spectroscopy (MAS NMR)

The ${ }^{27} \mathrm{Al}$ and ${ }^{29} \mathrm{Si}$ MAS NMR spectra were obtained at $11.7 \mathrm{~T}$ using a Bruker Avance 500 spectrometer and Doty MAS probes, one with a $4 \mathrm{~mm}$ silicon nitride rotor spun at up to 12 $\mathrm{kHz}$ for $\mathrm{Al}$ and one with a $5 \mathrm{~mm}$ zirconia rotor spun at up to $6 \mathrm{kHz}$ for $\mathrm{Si}$. The ${ }^{27} \mathrm{Al}-\mathrm{NMR}$ spectra were acquired at a spectrometer frequency of $130.244 \mathrm{MHz}$ with a $15^{\circ}$ pulse of $1 \mu \mathrm{s}$ ( $\pi / 10$ pulse for solution) and a recycle delay of $1 \mathrm{~s}$, and the spectra were referenced to $\mathrm{Al}\left(\mathrm{H}_{2} \mathrm{O}\right)^{3+}{ }_{6}$. The ${ }^{29} \mathrm{Si}$ NMR spectra were acquired at a spectrometer frequency of 99.926 MHz using a $90^{\circ}$ pulse of $6 \mu \mathrm{s}(\boldsymbol{\pi} / 10, \pi / 2)$ pulse and a recycle delay of $30 \mathrm{~s}$, and the spectra were referenced to tetramethylsilane (TMS).

v. Mechanical testing

All the compressive strength tests were carried out in triplicate where sufficient raw material was available to prepare the $30 \mathrm{~mm}$ cubes. A number of different compositions were investigated in preliminary trials on smaller cylindrical samples, and the most promising compositions were then selected for fabrication into cubic samples which were tested using an ADR-auto compression testing machine (ELE International, UK). Only the results of the cubic samples are reported here. 


\section{Results and discussion}

\section{Characterization of raw materials}

\section{Chemical analysis}

The chemical compositions of the raw materials are given in Table 1 (Page 7). Geopolymers were prepared from the as-received raw red mud and bauxite, and also from the raw materials calcined at $500{ }^{\circ} \mathrm{C}$ for $24 \mathrm{~h}$ to improve their reactivity to alkali. The calcination temperature was based on the thermal analysis results (below).

Table 1 shows that the red mud consists primarily of $\mathrm{Fe}_{2} \mathrm{O}_{3}, \mathrm{Al}_{2} \mathrm{O}_{3}, \mathrm{SiO}_{2}, \mathrm{TiO}_{2}, \mathrm{Na}_{2} \mathrm{O}$ and $\mathrm{CaO}$, whereas the bauxite contains $\mathrm{Al}_{2} \mathrm{O}_{3}, \mathrm{Fe}_{2} \mathrm{O}_{3}$ and $\mathrm{TiO}_{2}$ as the main components. Alumina comprises almost $50 \%$ of the bauxite as would be expected for an aluminium ore. Nevertheless, the content of alumina is still reasonably high in red mud eventhough much of it has been extracted by the Bayer process, which also involves the addition of caustic soda, explaining the high sodium compared with bauxite. The alumina and sodium contents of red mud suggest that this waste might be a good source material for geopolymer formation. 


\section{Mineralogical analysis}

Figure 11 and 12 show the XRD traces of red mud and bauxite respectively. Both contain hematite $\left(\mathrm{Fe}_{2} \mathrm{O}_{3}\right)$, anatase $\left(\mathrm{TiO}_{2}\right)$ and boehmite $(\mathrm{AlO}(\mathrm{OH}))$. In the red mud other crystalline phases were iron oxide hydroxide $(\mathrm{FeO}(\mathrm{OH}))$ and sodium aluminium sulphide silicate hydrate $\left(\mathrm{Na}_{8}\left(\mathrm{Al}_{6} \mathrm{Si}_{6} \mathrm{O}_{24}\right) \mathrm{S} .4 \mathrm{H}_{2} \mathrm{O}\right)$. Bauxite also contains gibbsite $\mathrm{Al}(\mathrm{OH})_{3}$ and kaolinite $\left(\mathrm{Al}_{2} \mathrm{Si}_{2} \mathrm{O}_{5}(\mathrm{OH})_{4}\right)$.Upon calcination, some of the hydrous minerals were decomposed into other phases, while others disappeared altogether. The minerals gibbsite, bohmite, kaolinite and goethite were not found in the calcined materials, having been thermally decomposed at 500 ${ }^{\circ} \mathrm{C}[47]$. Calcined red mud contained only hematite, sodalite, anatase and arizonite (FeTiO) while calcined bauxite contained only titanium iron oxide and anatase. In both raw materials, the crystalline aluminium minerals are absent, having been thermally decomposed. 


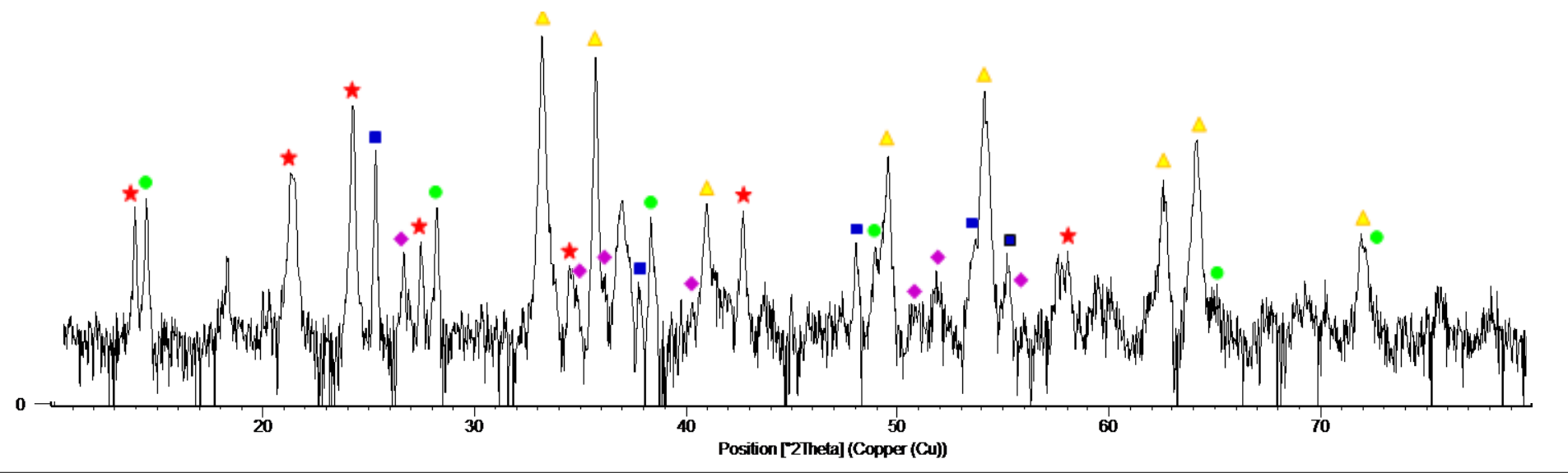

$\Delta=$ Hematite (04-004-8410), $\boldsymbol{\square}=$ Anatase (04-001-7641), $\bullet=$ Boehmite (04-013-2972) $\star \star$ =Sodium aluminium sulfide silicate hydrate (00-038-0515), $\bullet=$ Iron Oxide Hydroxide (04-010-0688)

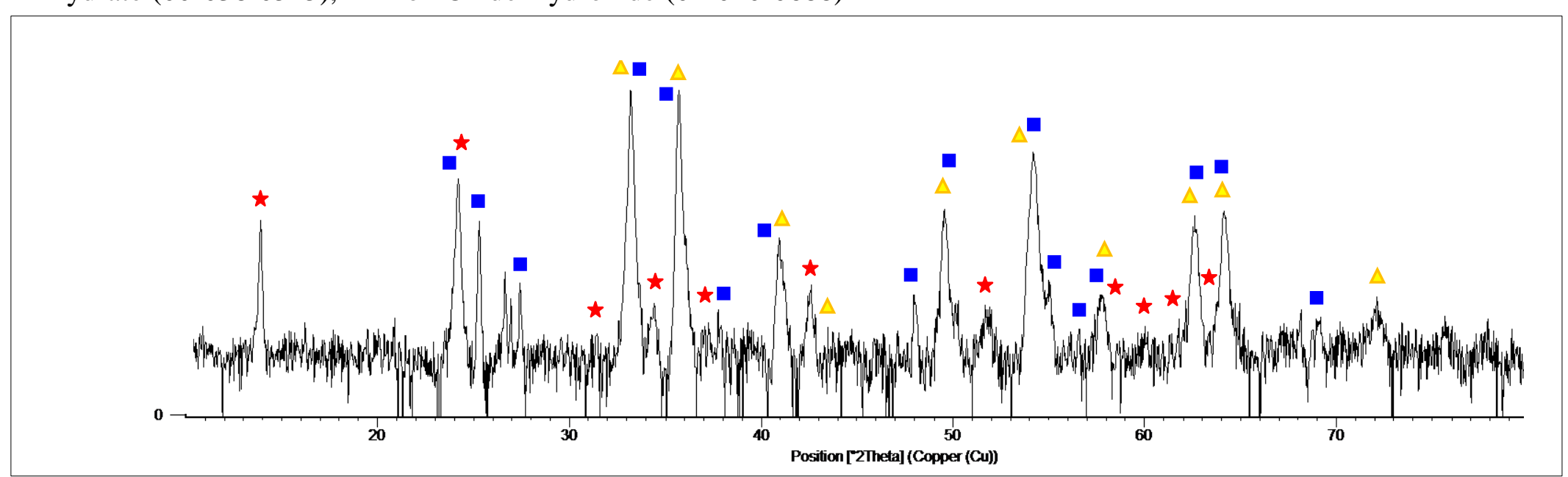

$\Delta=$ Hematite $(00-024-0072), \boldsymbol{\square}=$ Arizonite $(00-006-0227), \star=$ Sodalite $(00-052-0146)$

Figure 11: X-ray diffraction patterns of raw red mud (top) and calcined red mud (bottom). 


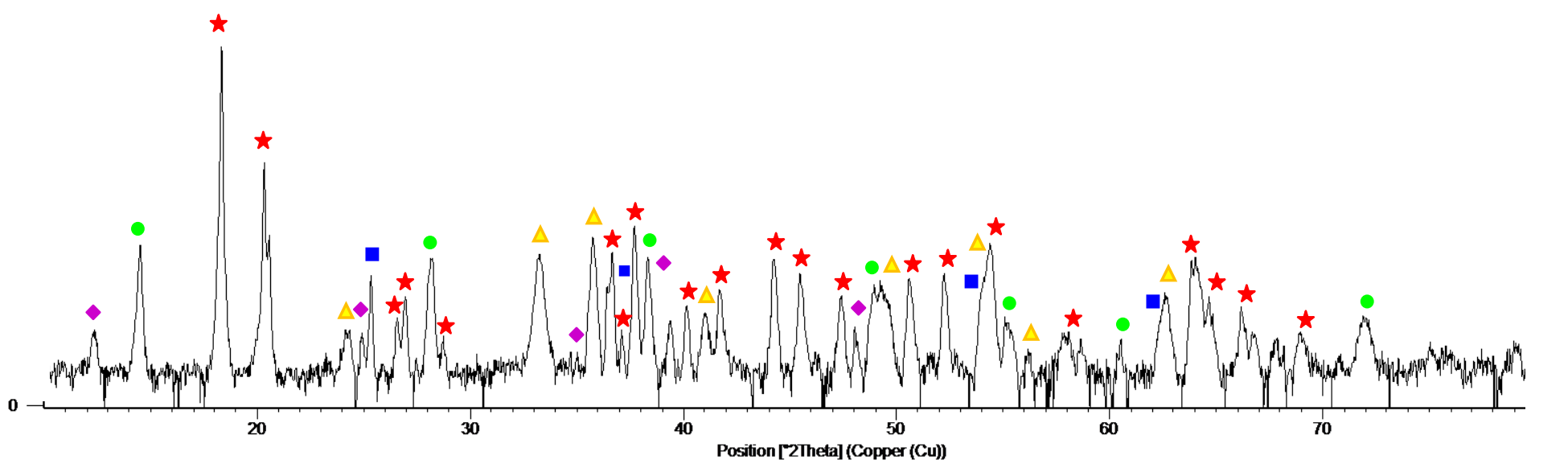

$\Delta=$ Hematite (04-003-5818), $\square=$ Anatase (01-083-2243),$\bullet=$ Boehmite $(01-074-2899), \star=$ Gibbsite $(00-029-0041)$,

$\bullet=$ Kaolinite (00-058-2006).

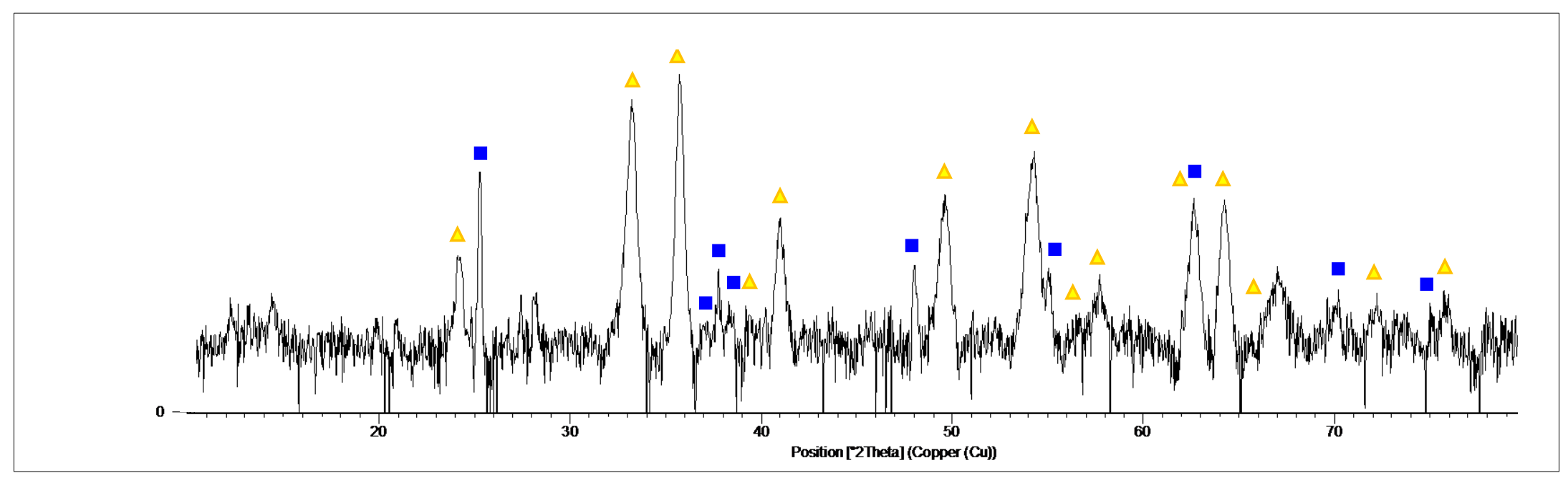

$\Delta=$ Titanium iron oxide (04-009-6569), $\square=$ Anatase (04-006-9241)

Figure 12: X-ray diffraction patterns of raw bauxite (top) and calcined bauxite (bottom). 


\section{Thermal analysis}

The raw materials were subjected to thermal analysis to determine the thermal decomposition temperatures of their mineral components [48]. Figure 13 and 14 presents the DCS-TGA curves of red mud and bauxite respectively. The DSC curve of red mud shows broad endothermic peak spread between 20 and $250{ }^{\circ} \mathrm{C}$ with a maximum at $260{ }^{\circ} \mathrm{C}$. This result is confirmed by the TGA curve in which there occurs a gradual mass loss in the temperature range of 20 and $500{ }^{\circ} \mathrm{C}$. Red mud shows a mass loss of $11.0 \%$ at $500{ }^{\circ} \mathrm{C}$. On the other hand, the DSC curve of bauxite shows an endothermic peak between 225 and $325^{\circ}$ Cand has a maximum at $280^{\circ} \mathrm{C}$ corresponding to dehydroxylation of bohmite, gibbsite and kaolinite [49]. This is consistent with a mass loss between 225 and $325^{\circ} \mathrm{C}$ on TGA curve. The total weight loss for bauxite at $500{ }^{\circ} \mathrm{C}$ is $23.84 \%$.

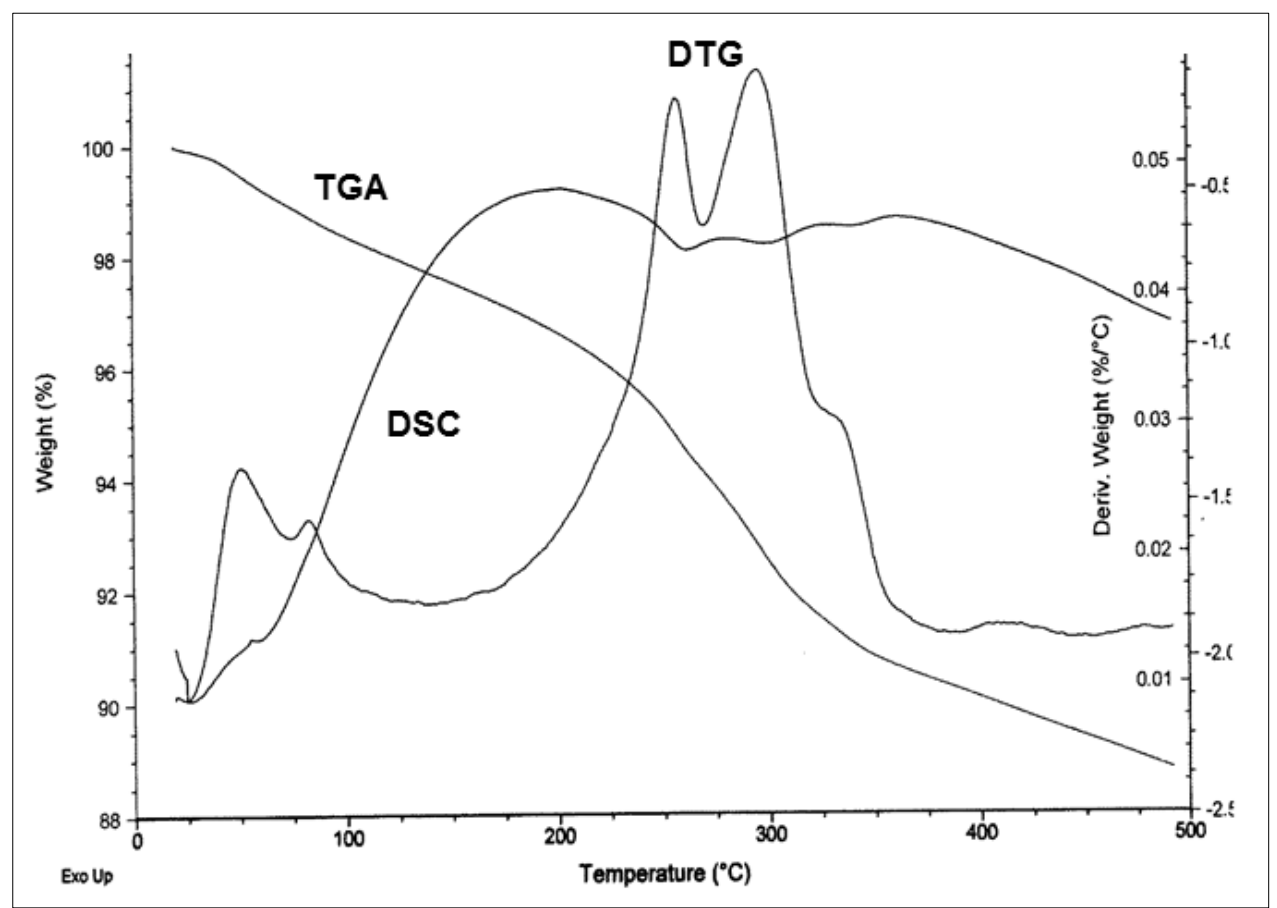

Figure 13: DSC-TGA curves of raw red mud. 


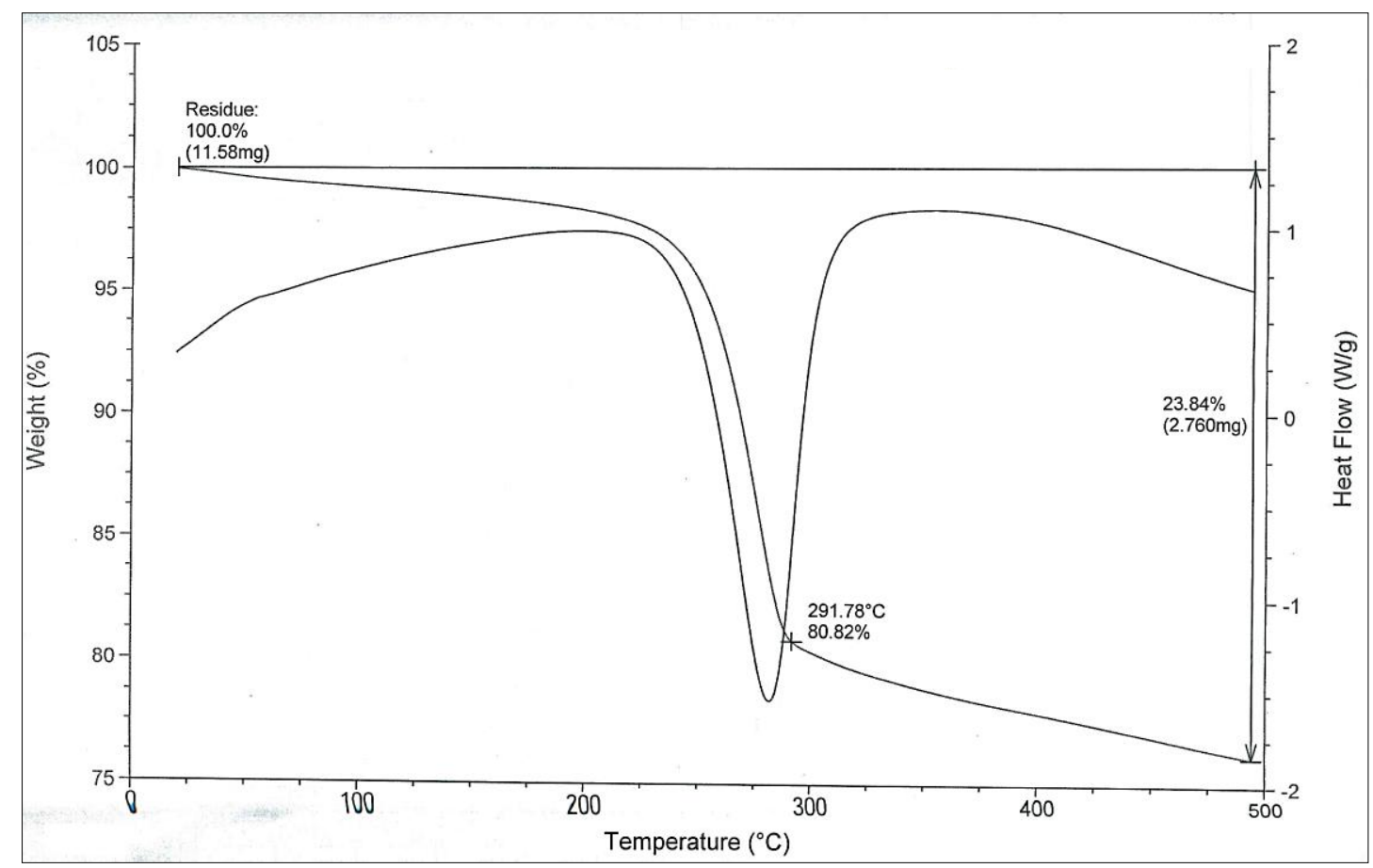

Figure 14: DSC-TGA curves of Australian bauxite. 


\section{SEM micrography}

SEM micrographs of the raw materials shown in Figure 15 reveal that neither shows a specific crystalline morphology. The particles are relatively loose, with high porosity and an average particle size of about $5 \mu \mathrm{m}$. Mass percentages of elements obtained using EDS shown in Table 4 confirm that $\mathrm{Al}$ and $\mathrm{Fe}$ are the major components of red mud, while $\mathrm{Al}$ is the principal component of the bauxite.
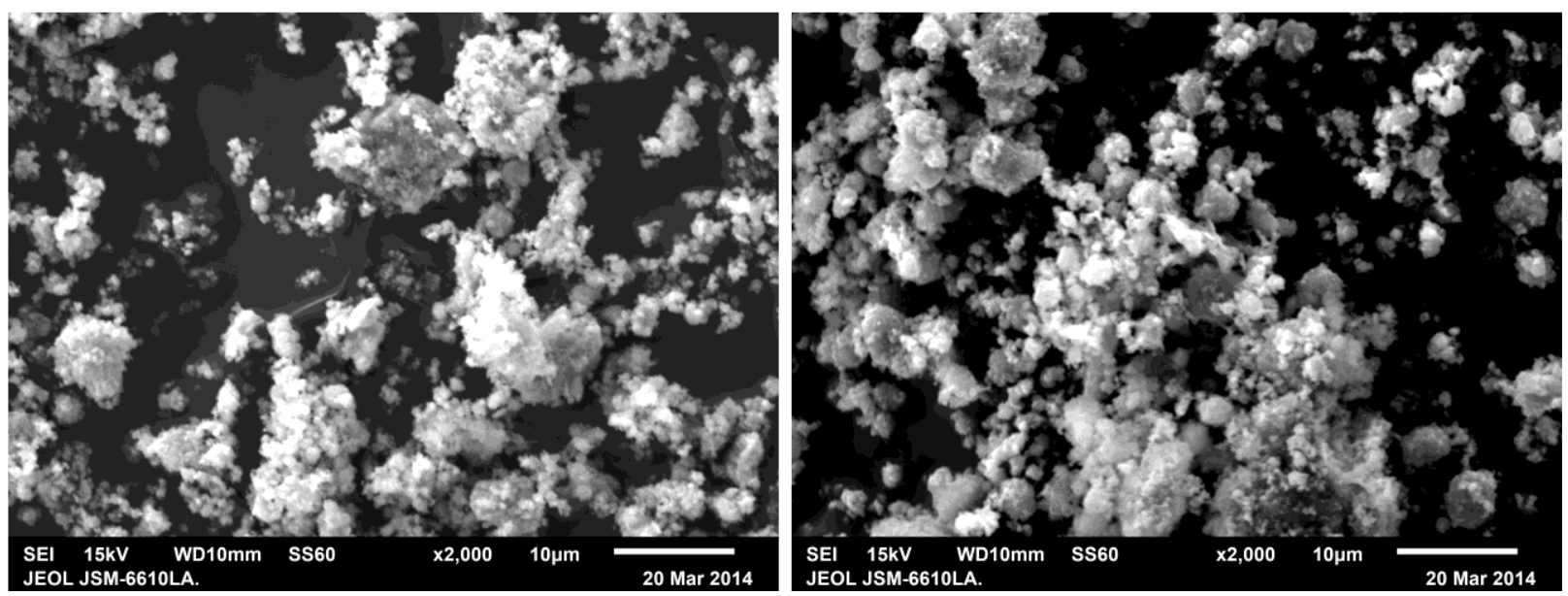

Figure 15: SEM micrographs of red mud (left) and bauxite (right).

\begin{tabular}{|c|c|c|c|c|c|}
\hline Red mud element x2k & Mass \% & Atom \% & Bauxite element & Mass \% & Atom \% \\
\hline $\mathrm{O}$ & 36.0 & 56.0 & $\mathrm{O}$ & 41.2 & 57.3 \\
$\mathrm{Na}$ & 6.8 & 7.4 & $\mathrm{Mg}$ & 0.2 & 0.1 \\
$\mathrm{Al}$ & 15.6 & 14.4 & $\mathrm{Al}$ & 40.6 & 33.5 \\
$\mathrm{Si}$ & 7.1 & 6.4 & $\mathrm{Si}$ & 4.2 & 3.3 \\
$\mathrm{P}$ & 0.2 & 0.2 & $\mathrm{P}$ & 0.2 & 0.1 \\
$\mathrm{Ca}$ & 0.3 & 0.2 & $\mathrm{~S}$ & $<0.1$ & $<0.1$ \\
$\mathrm{Ti}$ & 3.9 & 2.0 & $\mathrm{Cl}$ & 0.3 & 0.2 \\
$\mathrm{Fe}$ & 30.1 & 13.4 & $\mathrm{~K}$ & 0.1 & $<0.1$ \\
& & & $\mathrm{Ti}$ & 1.4 & 0.7 \\
& & & $\mathrm{Fe}$ & 11.7 & 4.7 \\
\hline Total & 100 & 100 & Total & 100 & 100 \\
\hline
\end{tabular}

Table 4: Global elemental analysis of red mud and bauxite from EDS analysis. 


\section{Characterization of the geopolymer samples}
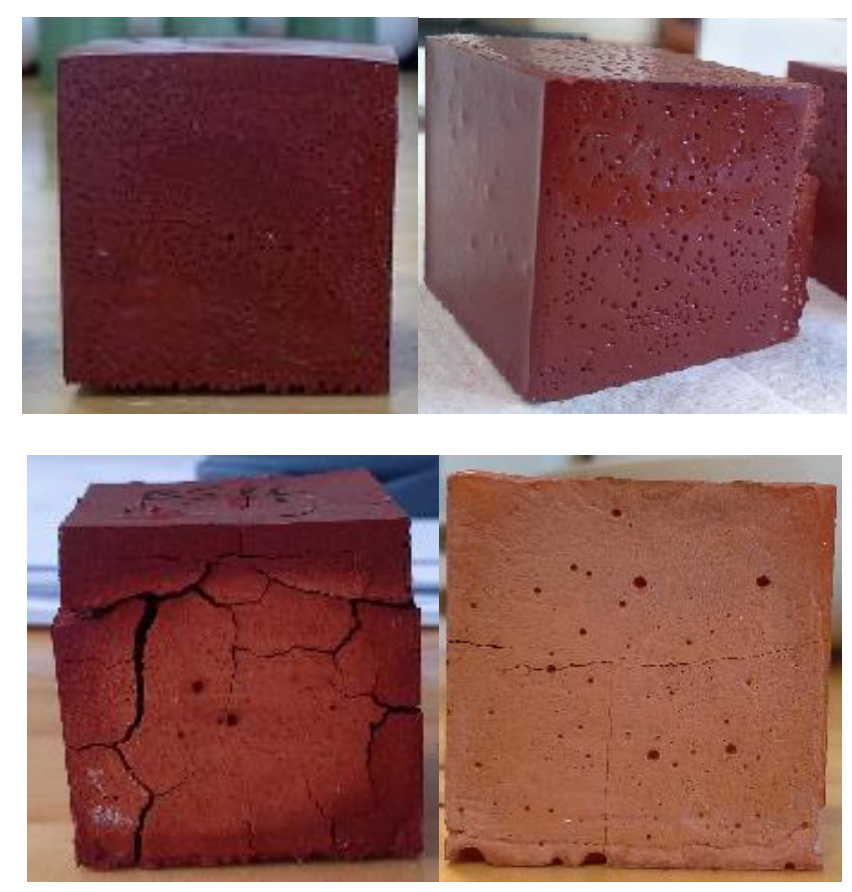

Figure 16: No cracking shown by the good geopolymers (top) and some extensive cracking shown by the weak geopolymer samples (bottom).

\section{Compressive strength of red mud samples}

The results of strength test on the red mud geopolymer samples show wide variations in compressive strength, from 9.59 to $58.13 \mathrm{MPa}$, (Table 5). The lowest strength was given by RMS6 which contains calcined red mud, $\mathrm{NaOH}, \mathrm{SiO}_{2}$ fume and water while the highest strength was given by RMS4 which were made from calcined red mud, sodium silicate "D", $\mathrm{SiO}_{2}$ fume and water. The only difference between these two samples is the sodium source, which was $\mathrm{NaOH}$ in RMS6 and sodium silicate "D" in RMS4. 


\begin{tabular}{ccc}
\hline Sample & $\begin{array}{c}\text { Average } \\
\text { strength, MPa }\end{array}$ & $\begin{array}{c}\text { Standard } \\
\text { deviation, MPa }\end{array}$ \\
\hline RMS1 & 24.90 & 0.78 \\
RMS2 & 37.90 & 9.48 \\
RMS3 & 44.33 & 2.84 \\
RMS4 & 58.13 & - \\
RMS5 & 17.25 & 1.49 \\
RMS6 & 9.59 & 0.64 \\
\hline BS1 & 28.15 & 2.35 \\
BS2 & 28.50 & 2.80 \\
BS3 & 17.77 & 4.79 \\
BS4 & cracked & - \\
BS5 & 14.24 & 2.47 \\
\hline
\end{tabular}

Table 5: Compressive strength and standard deviation of geopolymer samples.

The geopolymers made from uncalcined red mud, namely RMS1, RMS3 and RMS5 give quite good strengths, comparable to samples made from the calcined red mud. The difference between calcined and uncalcined red mud is their reactivity in the geopolymerisation reaction. Generally, calcined materials show higher reactivity, because during calcination, most of the crystalline phases in the raw materials become amorphous and are hence more reactive towards alkali attack [50, 51]. Nevertheless this is not necessarily the case here, as seen from the mechanical strengths (Table 5). For instance, a mean compressive strength of $44.33 \mathrm{MPa}$ was given by the RMS3 samples, which is the second highest strength of all the samples. The RMS3 samples were made from uncalcined red mud with sodium silicate "D", $\mathrm{SiO}_{2}$ fume and water. This mixture is the same as the one used for making RMS4, the geopolymer sample with the highest strength. Visual observations of the as-cured samples show that some of these compositions had shrunk and contained drying cracks (Fig. 16); these influenced the strengths of the samples more than the composition. However, the composition, particularly the water content, influences the drying behaviour, and hence the strength. 
Nevertheless, the compressive strengths of these geopolymers compare very satisfactorily with those of other workers aiming to prepare construction materials by alkali activation of mixtures of other wastes with red mud (Table 6). In many of these other composite materials, the proportion of red mud is small, and the compressive strengths are probably derived principally from the geopolymer binder. Since the aim of the present work was to produce viable and strong materials without the addition of significant amounts of other components (apart from the need to make slight adjustments to optimise the overall red mud or bauxite composition), the present materials readily meet the objectives of this project.

\begin{tabular}{|l|l|l|}
\hline Geopolymers & $\begin{array}{l}\text { Compressive } \\
\text { strength, MPa }\end{array}$ & Reference \\
\hline Red mud with fly ash & 13 & [17] Zhang, He et al. 2010 \\
\hline Red mud with fly ash & 13 & [16] He, Zhang et al. 2012 \\
\hline Red mud with fly ash (5:95) & $\sim 29$ & [18] Kumar and Kumar 2013 \\
\hline Red mud with fly ash (85 wt \%) & 5.5 & [19] Mucsi, Lakatos et al. 2014 \\
\hline Red mud with metakaolin (85:15) & 20.5 & [38] Dimas, Giannopoulou et al. 2009 \\
\hline Red mud with metakaolin & 10.8 & [52] Hajjaji, Andrejkovičová et al. 2013 \\
\hline Red mud with metakaolin (10\%) & $\sim 21$ & [21] Mira, Danka et al. 2013 \\
\hline Red mud with rice husk ash & 20.5 & [22] He, Jie et al. 2013 \\
\hline $\begin{array}{l}\text { Red mud with granulated blast } \\
\text { furnace slag (mass ratio of 5:5) }\end{array}$ & 49.2 & [23] Ye, Yang et al. 2014 \\
\hline $\begin{array}{l}\text { Red mud with portland cement } \\
\text { (8 wt \%) }\end{array}$ & 17.2 & [24]Ivana, Mira et al. 2013 \\
\hline
\end{tabular}

Table 6: Comparison of the compressive strengths reported by other workers for red mud composites with other waste materials 


\section{Compressive strength of bauxite samples}

The compressive strengths of the bauxite geopolymers are generally lower than for the red mud samples. The lowest compressive strength was given by BS5 and the strongest was BS2. BS5 was made from uncalcined bauxite, $\mathrm{NaOH}, \mathrm{SiO}_{2}$ fume and water, while $\mathrm{BS} 2$ was made from calcined bauxite, $\mathrm{NaOH}$, sodium silicate "D" and $\mathrm{SiO}_{2}$ fume. Sodium silicate "D" was used as the source of liquid for sample BS2, which contained no additional water. Other workers have mixed sodium silicate with $\mathrm{KOH}$ or $\mathrm{NaOH}$ to prepare the alkaline activators with molarities in the range 7-10M [53] and have shown that these improve the strength of the geopolymer. In the

present case, the higher strength was developed in samples activated with a mixture of alkali silicate and alkali, consistent with this general rule. Furthermore, calcined materials generally produce stronger geopolymers since they are more reactive to alkali and form better networks of inorganic units, provided the calcination temperature is not so high as to form less reactive crystalline products. The present results for bauxite geopolymers are also consistent with this general rule, since sample BS2 contained calcined bauxite. 

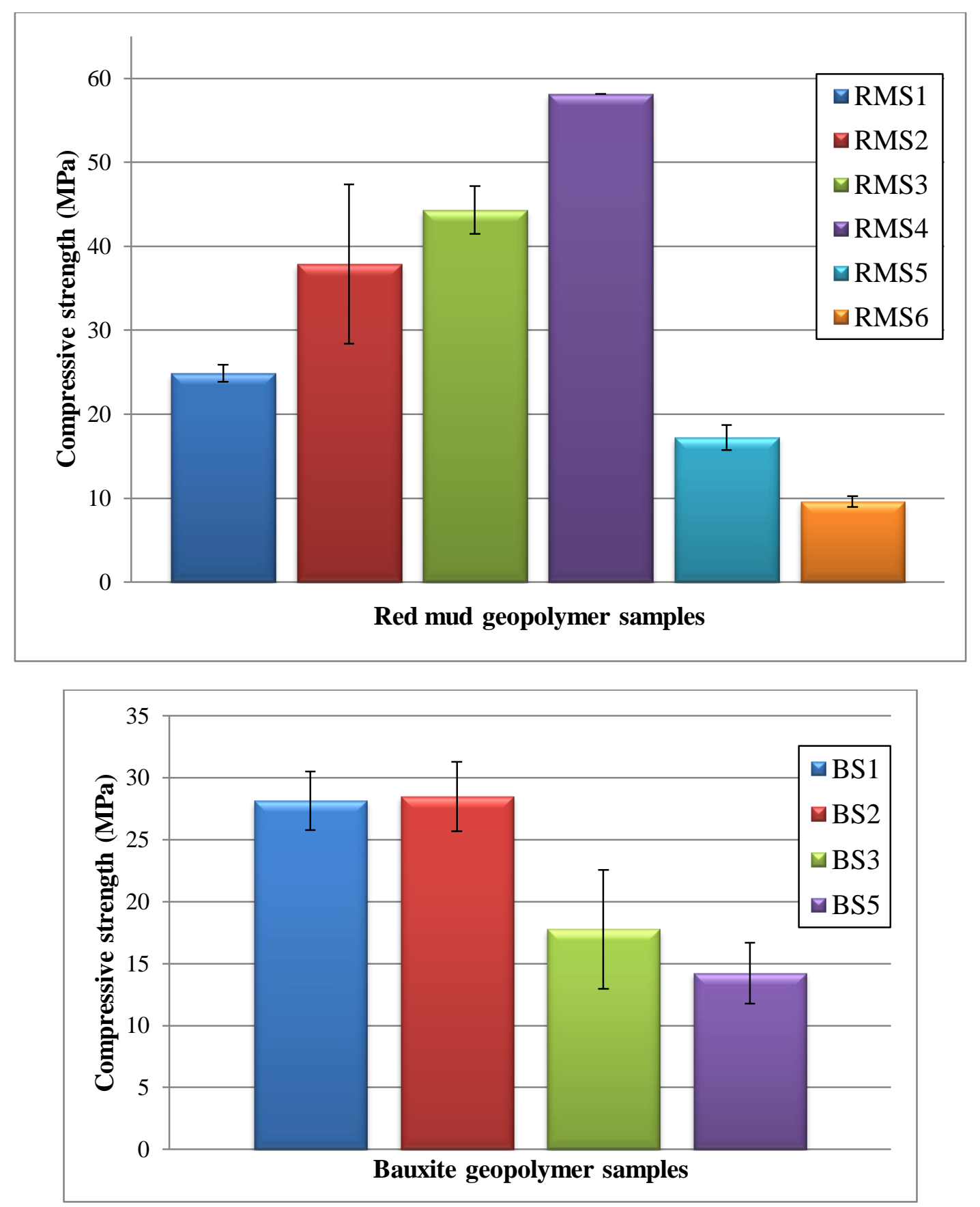

Figure 17: 21 day compressive strengths of red mud and bauxite geoplolymer samples. Error bars represent one standard deviation. (Note that BS4 samples were cracked prior to testing and are not shown.) 
To summarise, the highest compressive strengths were obtained from the red mud geopolymers which had been calcined (RMS2, RMS4, ) but this is clearly not the only factor operating, since geopolymer RMS3, prepared from uncalcined red mud, also showed a good compressive strength. The strengths of all the red mud geopolymers apart from RMS5 and RMS6 are sufficiently good for these materials to be considered for low load-bearing construction applications. It should be noted that the two weakest geopolymers RMS5 and RMS6 do not contain sodium silicate.

The cracking of the geopolymers is clearly a major drawback to the development of strength. As suggested above, this appears to be the result of drying problems and is related to the amount of water in the geopolymer mixture, which is very crucial. Weng and Sagoe [54] pointed out that water takes part in all of the geopolymerisation steps. It acts as the medium during the dissolution of aluminosilicate materials, transportation of dissolved $\mathrm{Al}^{3+}$ and $\mathrm{Si}^{4+}$ compounds, and polymerisation of various aluminate- and silicate-hydroxyl species. Zuhua, Xiao et al. [36] proposed that there should be about $7.4 \%$ non-evaporable water in the mixture to produce geopolymers with good compressive strengths. In the present work, the amounts of water were kept to a minimum, consistent with maintaining the water to sodium ratio at about 10 . In some cases, additional water had to be added to the mixtures to make them workable. It is believed that this extra water added caused the geopolymer to develop drying cracks hence reduced its mechanical strength. To produce viable consistently strong materials from aluminium smelting wastes, this cracking problem must be solved, possibly by the use of a small amount of acetyl acetone or glycerol as a drying agent added to the geopolymer mixture [55]. 


\section{Mineralogical analyses}

\begin{tabular}{|l|c|c|c|c|}
\hline & Raw red mud & RMS1 & RMS3 & RMS5 \\
\hline Hematite & $\checkmark$ & $\checkmark$ & $\checkmark$ & X \\
\hline Anatase & $\checkmark$ & $\checkmark$ & X & $\checkmark$ \\
\hline Boehmite & $\checkmark$ & $\checkmark$ & $\checkmark$ & X \\
\hline $\begin{array}{l}\text { Sod Aluminium Sulfide } \\
\text { Silicate Hydrate }\end{array}$ & $\checkmark$ & X & X & X \\
\hline Iron oxide hydroxide & $\checkmark$ & X & $\checkmark$ & X \\
\hline Arizonite & X & X & X & $\checkmark$ \\
\hline Ilmenite & X & X & $\checkmark$ & $\checkmark$ \\
\hline
\end{tabular}

Table 7: Mineral assemblage in the uncalcined (as-received) red mud and the corresponding geopolymers.

Figure 17 compares the XRD patterns of as-received red mud and the geopolymers. Red mud contains the crystalline phases hematite, anatase, bohmite, sodium aluminium sulfide silicate hydrate and iron oxide hydroxide (Figure 18(a)). The XRD patterns of red mud and their corresponding geopolymers show differences in their mineral contents. No sodium aluminium hydrate or iron oxide hydroxides are found in any of the geopolymers, as shown by the loss of the XRD peaks at $43^{\circ} 2 \theta$ and $52^{\circ} 2 \theta$ respectively (Figs. $18(\mathrm{~b}), 18(\mathrm{c})$ and $18(\mathrm{~d})$ ). Hematite is still present as $\mathrm{Fe}_{2} \mathrm{O}_{3}$ in $\mathrm{RMS} 1$ and $\mathrm{RMS} 3$, but is converted to ilmenite, a titanium iron oxide mineral $\mathrm{TiFeO}_{3}$ in RMS5. It is not easy to distinguish these two minerals from each other since most of the peaks for both are located at the same position. This can also mean that a mixture of both minerals is present. Anatase is found in RMS1 and RMS5 but was converted to arizonite, $\mathrm{Fe}_{2} \mathrm{Ti}_{3} \mathrm{O}_{9}$ in $\mathrm{RMS} 3$. This is demonstrated by the decrease of the small peak of anatase at $48^{\circ} 2 \theta$ (Fig. 18(c)). Because the geopolymers were synthesised at room temperature, they all contain boehmite, which only disappeared when the red mud was fired at high temperature. The assemblage of minerals found in the as-received red mud and the corresponding geopolymers is shown in Table 7. 


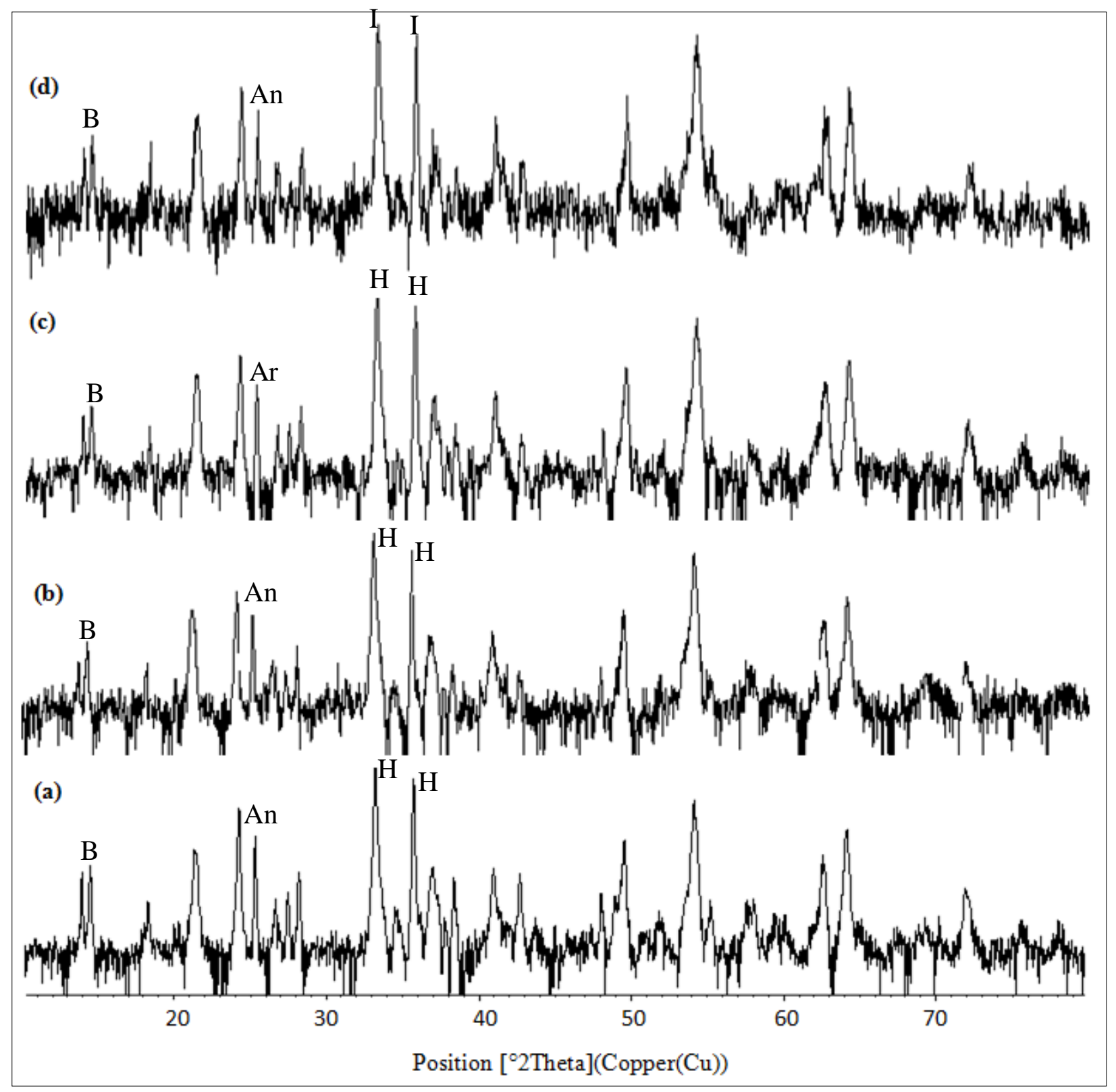

Figure 18: XRD diffractograms of (a) raw red mud, (b) RMS1, (c) RMS3 and (d) RMS5; $\mathrm{B}=$ boehmite, An=anatase, $\mathrm{I}=$ ilmenite, $\mathrm{H}=$ hematite, $\mathrm{Ar}=$ arizonite. 


\begin{tabular}{|l|c|c|c|c|}
\hline & Red mud 500 & RMS2 & RMS4 & RMS6 \\
\hline Hematite & $\checkmark$ & $\checkmark$ & $\checkmark$ & $\checkmark$ \\
\hline Arizonite & $\checkmark$ & $\checkmark$ & X & X \\
\hline Sodalite & $\checkmark$ & X & X & $\checkmark$ \\
\hline Anatase & X & X & $\checkmark$ & X \\
\hline Zeolite & X & X & $\checkmark$ & X \\
\hline
\end{tabular}

Table 8: Mineral assemblage in the calcined red mud and the corresponding geopolymers.

The minerals found in calcined red mud are hematite $\left(\mathrm{Fe}_{2} \mathrm{O}_{3}\right)$, arizonite $\left(\mathrm{Fe}_{2} \mathrm{Ti}_{3} \mathrm{O}_{9}\right)$ and sodalite $\left(\mathrm{Na}_{8}\left(\mathrm{Al}_{6} \mathrm{Si}_{6} \mathrm{O}_{24}\right) \mathrm{Cl}_{2}\right)$ as shown in Figure 19(a). Unlike the other minerals, hematite was found in all the geopolymer samples. In RMS2, arizonite still can be found which suggested it might not be involved in the geopolymer formation (Fig. 19(b). The geopolymerisation reaction has changed arizonite to anatase in RMS4, shown by the peak at $25.5^{\circ} 2 \theta$. It also changed sodalite to zeolite as shown by the slight shift in the sodalite peak at $14^{\circ} 2 \theta$ to $15^{\circ} 2 \theta$ (Figure 19(c)). These changes are not complete, as evidenced by the retention of some of the arizonite and sodalite peaks in RMS4. Meanwhile, in RMS6, the parent hematite and sodalite are still present, as shown by the major sodalite peak at $14^{\circ} 2 \theta$ (Fig. 19(d)). The assemblage of minerals found in the calcined red mud and the corresponding geopolymers is shown in Table 8 . 


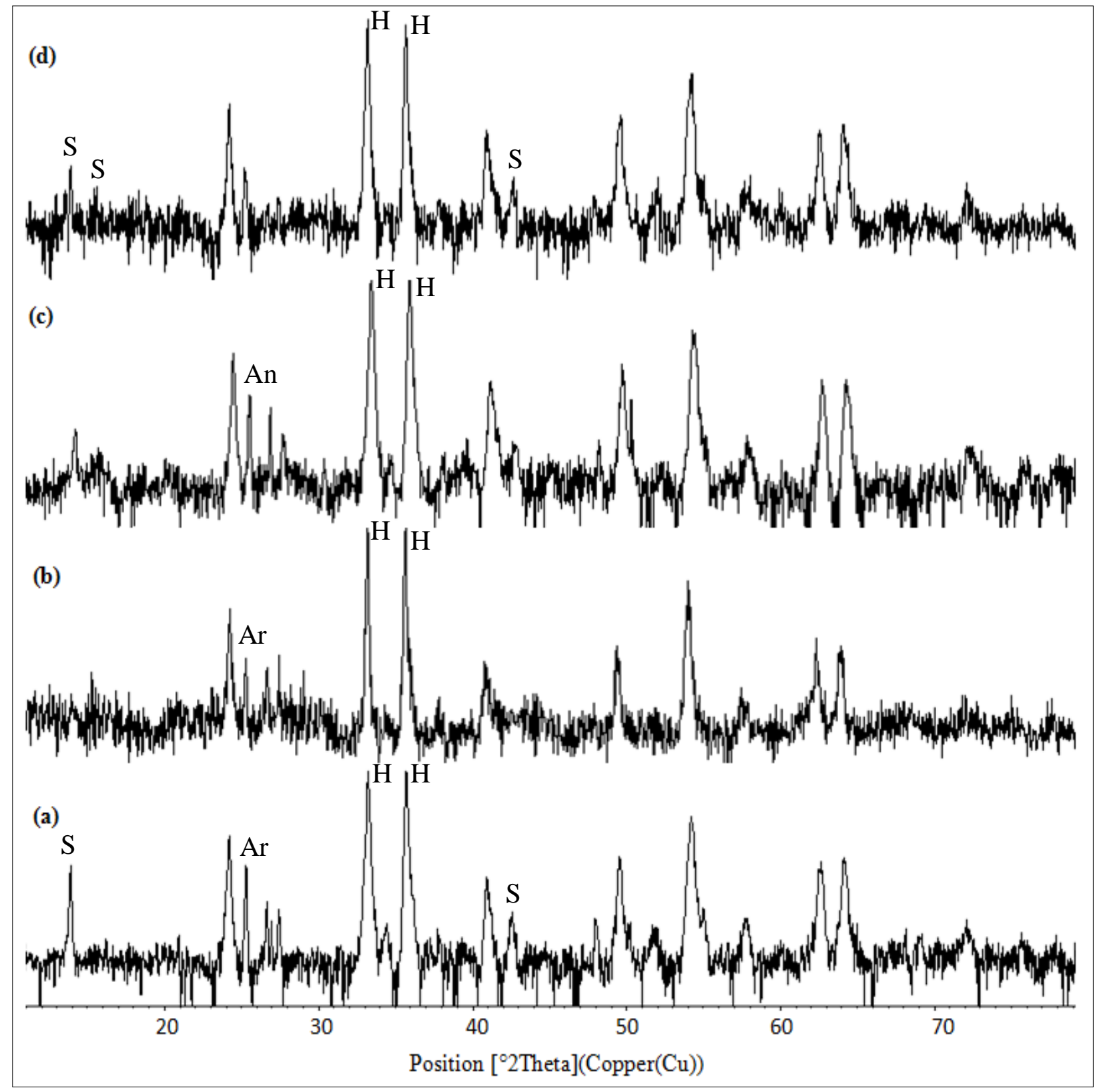

Figure 19: XRD diffractograms of (a) calcined red mud, (b) RMS2, (c) RMS4 and (d) RMS6; $\mathrm{S}=$ sodalite, $\mathrm{An}=$ anatase, $\mathrm{H}=$ hematite, $\mathrm{Ar}=$ arizonite. 


\begin{tabular}{|l|c|c|c|c|}
\hline & Raw bauxite & BS1 & BS3 & BS5 \\
\hline Hematite & $\checkmark$ & X & $\checkmark$ & X \\
\hline Anatase & $\checkmark$ & $\checkmark$ & $\checkmark$ & $\checkmark$ \\
\hline Boehmite & $\checkmark$ & $\checkmark$ & $\checkmark$ & X \\
\hline Gibbsite & $\checkmark$ & $\checkmark$ & $\checkmark$ & X \\
\hline Kaolinite & $\checkmark$ & X & $\checkmark$ & $\checkmark$ \\
\hline Titanium iron oxide & X & X & X & $\checkmark$ \\
\hline Zeolite & X & X & X & X \\
\hline Iron titanium oxide & X & $\checkmark$ & & $\checkmark$ \\
\hline
\end{tabular}

Table 9: Mineral assemblage in the uncalcined (as-received) bauxite and the corresponding geopolymers.

Figure 20(a) presents the XRD patterns of as-received bauxite and its geopolymers. The diffractogram contains sharp peaks from crystalline phases of hematite, anatase, bohmite, gibbsite and kaolinite. This suggests that amorphous phases are not present in large quantity and insufficient for the geopolymerisation reaction. BS1 contains anatase, bohmite and gibbsite from the parent materials, and an additional iron titanium oxide. Meanwhile BS3 shows all of the minerals found in its starting bauxite, and also a new titanium iron oxide (Fig. 20(c)). The XRD trace of BS5 is more complicated (Fig. 20(c)), containing only bohmite and the newly-formed new phases titanium iron oxide and zeolite. The assemblage of minerals found in the uncalcined (as-received) bauxite and the corresponding geopolymers is shown in Table 9. 


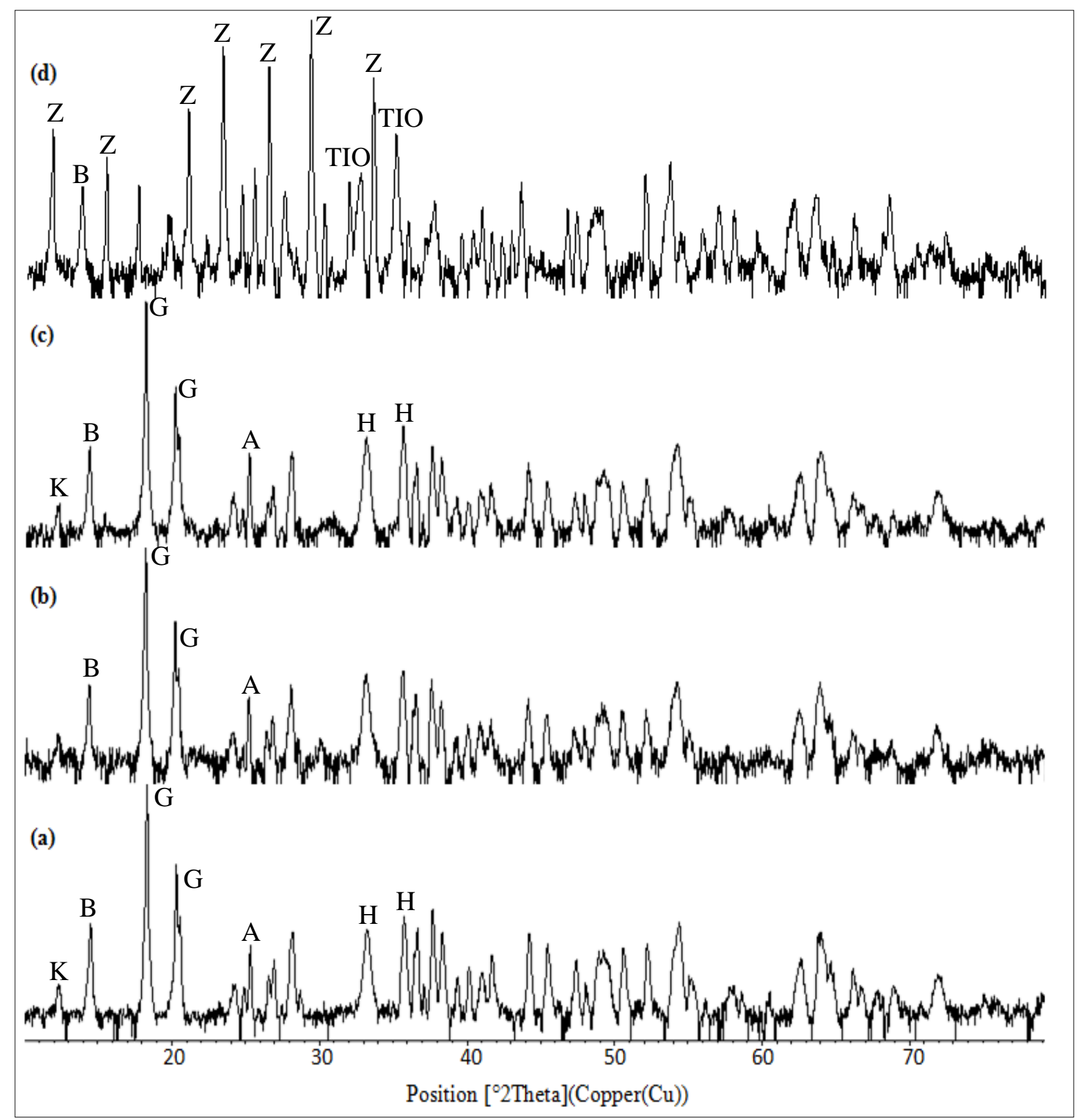

Figure 20: XRD diffractograms of (a) raw bauxite, (b) BS1, (c) BS3 and (d) BS5; Z=zeolite, $\mathrm{B}=$ =boehmite, $\mathrm{TIO}=$ titanium iron oxide, $\mathrm{K}=$ kaolinite, $\mathrm{A}=$ anatase, $\mathrm{H}=$ hematite. 


\begin{tabular}{|l|c|c|c|}
\hline & Bauxite 500 & BS2 & BS4 \\
\hline Titanium iron oxide & $\checkmark$ & X & X \\
\hline Anatase & $\checkmark$ & $\checkmark$ & X \\
\hline Hematite & X & $\checkmark$ & $\checkmark$ \\
\hline Titanium aluminium oxide & X & X & $\checkmark$ \\
\hline
\end{tabular}

Table 10: Mineral assemblage in the calcined bauxite and the corresponding geopolymers.

Figure 21 shows the XRD images of calcined bauxite and its geopolymers. Due to the thermal treatment, calcined bauxite contained only anatase and titanium iron oxide (Fig. 21(a)). After geopolymer formation, anatase is still present in sample BS2 but titanium iron oxide was converted to titanium aluminium oxide during the reaction (Fig. 21(b)). Sample BS4 contains hematite and titanium aluminium oxide (Figure 21(c)).

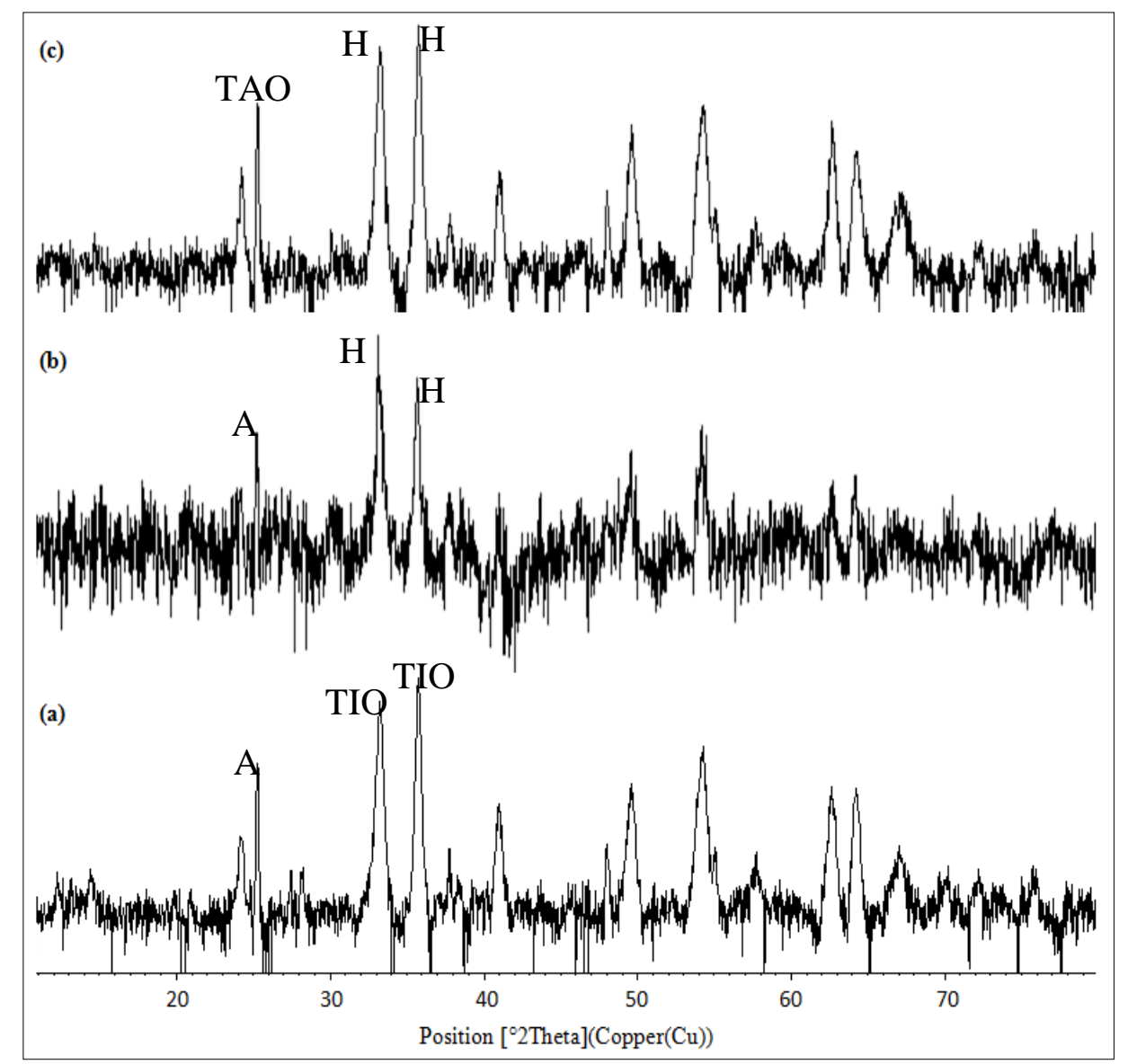

Figure 21: XRD diffractograms of (a) calcined bauxite, (b) BS2 and (c) BS4;

TAO=titanium aluminium oxide, $\mathrm{H}=$ hematite, $\mathrm{A}=$ anatase, $\mathrm{TIO}=$ titanium iron oxide. 
Generally the parent peaks in starting materials are still present in the geopolymers. This indicates that the crystalline phases are not involved in the geopolymer formation. It is well known that only amorphous phases in raw materials are reactive to alkali and involved in geopolymerisation. The major crystalline content of the geopolymers may therefore be acting as inactive fillers and not contributing to the strength of the geopolymer binder.

\begin{tabular}{|c|c|c|c|}
\hline Samples & Main X-ray peaks & Ref code & Chemical formula \\
\hline \multirow[t]{3}{*}{ RMS1 } & Hematite, syn & $04-007-9266$ & $\mathrm{Fe} 2 \mathrm{O} 3$ \\
\hline & Bohmite & 01-074-2899 & $\mathrm{AlO}(\mathrm{OH})$ \\
\hline & Anatase, syn & 04-006-1918 & $\mathrm{TiO} 2$ \\
\hline \multirow[t]{2}{*}{ RMS2 } & Hematite, syn & 04-002-2983 & $\mathrm{Fe} 2 \mathrm{O} 3$ \\
\hline & Arizonite & 00-029-1494 & $\mathrm{Fe} 2 \mathrm{Ti} 3 \mathrm{O} 9$ \\
\hline \multirow[t]{3}{*}{ RMS3 } & Iron oxide & 04-006-6579 & $\mathrm{Fe} 2 \mathrm{O} 3$ \\
\hline & Bohmite, syn & 04-010-5684 & $\mathrm{AlO}(\mathrm{OH})$ \\
\hline & Arizonite & 00-029-1494 & $\mathrm{Fe} 2 \mathrm{Ti3O} 9$ \\
\hline \multirow[t]{4}{*}{ RMS4 } & Hematite, syn & 04-006-0285 & $\mathrm{Fe}_{2} \mathrm{O}_{3}$ \\
\hline & Anatase low, syn & 01-072-7058 & $\mathrm{TiO}_{2}$ \\
\hline & Hematite HP & $01-072-6227$ & $\mathrm{Fe}_{2} \mathrm{O}_{3}$ \\
\hline & Zeolite TMA & 01-073-6389 & $\mathrm{Na}_{9.4} \mathrm{Al}_{9.4} \mathrm{Si}_{26.6} \mathrm{O}_{72}\left(\mathrm{H}_{2} \mathrm{O}\right)_{36.8}$ \\
\hline \multirow[t]{3}{*}{ RMS5 } & Ilmenite & $04-012-1150$ & $\mathrm{TiFeO}_{3}$ \\
\hline & Anatase low, syn & 01-072-7058 & $\mathrm{TiO}_{2}$ \\
\hline & Bohmite & 04-010-5683 & $\mathrm{AlO}(\mathrm{OH})$ \\
\hline \multirow[t]{2}{*}{ RMS6 } & Hematite, syn & 01-076-8393 & $\mathrm{Fe}_{2} \mathrm{O}_{3}$ \\
\hline & Sodalite & $00-052-0145$ & $\mathrm{Na}_{8} \mathrm{Mg}_{3} \mathrm{Si}_{9} \mathrm{O}_{24}(\mathrm{OH})_{2}$ \\
\hline
\end{tabular}




\begin{tabular}{|c|c|c|c|}
\hline Samples & Main X-ray peaks & Ref code & Chemical formula \\
\hline BS1 & $\begin{array}{c}\text { Iron titanium oxide } \\
\text { Bohmite } \\
\alpha-\mathrm{Al}(\mathrm{OH})_{3} \\
\text { Anatase }\end{array}$ & $\begin{array}{l}00-054-1267 \\
01-074-2898 \\
00-012-0460 \\
01-075-2551\end{array}$ & $\begin{array}{l}\mathrm{Fe}_{9} \mathrm{TiO}_{15} \\
\mathrm{AlO}(\mathrm{OH}) \\
\mathrm{Al}(\mathrm{OH})_{3} \\
\mathrm{TiO}_{2}\end{array}$ \\
\hline BS2 & $\begin{array}{c}\text { Hematite } \\
\text { Anatase } \\
\text { Palladium } \\
\text { bis(hydroxyanthrapyrimidine) }\end{array}$ & $\begin{array}{l}01-072-6225 \\
01-075-2546 \\
00-048-1946\end{array}$ & $\begin{array}{c}\mathrm{Fe}_{2} \mathrm{O}_{3} \\
\mathrm{TiO}_{2} \\
\mathrm{C}_{30} \mathrm{H}_{14} \mathrm{~N}_{404} \mathrm{Pd}\end{array}$ \\
\hline BS3 & $\begin{array}{c}\text { Gibbsite } \\
\text { Titanium Iron Oxide } \\
\text { Bohmite } \\
\text { Anatase } \\
\text { Kaolinite } \\
\text { Hematite }\end{array}$ & $\begin{array}{l}00-029-0041 \\
04-009-6569 \\
00-021-1307 \\
01-075-2544 \\
00-058-2006 \\
01-072-6226\end{array}$ & $\begin{array}{c}\mathrm{Al}(\mathrm{OH})_{3} \\
\mathrm{Ti}_{0.228} \mathrm{Fe}_{1.698} \mathrm{O}_{3} \\
\mathrm{AlO}(\mathrm{OH}) \\
\mathrm{TiO}_{2} \\
\mathrm{Al}_{2} \mathrm{Si}_{2} \mathrm{O}_{5}(\mathrm{OH})_{4} \\
\mathrm{Fe}_{2} \mathrm{O}_{3}\end{array}$ \\
\hline BS4 & $\begin{array}{c}\text { Diiron(III) oxide } \\
\text { Titanium aluminium oxide }\end{array}$ & $\begin{array}{l}01-089-8104 \\
04-008-2509\end{array}$ & $\begin{array}{c}\mathrm{Fe}_{2} \mathrm{O}_{3} \\
\mathrm{Ti}_{0.984} \mathrm{Al}_{0.016} \mathrm{O}_{1.992}\end{array}$ \\
\hline BS5 & $\begin{array}{c}\text { Zeolite } \mathrm{A}, \mathrm{Na}) \\
\text { Titanium Iron Oxide } \\
\text { Bohmite } \\
\text { Anatase }\end{array}$ & $\begin{array}{l}00-039-0222 \\
04-009-5898 \\
04-014-2197 \\
01-071-1167 \\
\end{array}$ & $\begin{array}{c}\mathrm{Na}_{96} \mathrm{Al}_{96} \mathrm{Si}_{96} \mathrm{O}_{384} \cdot 216 \mathrm{H}_{2} \mathrm{O} \\
\mathrm{Ti}_{0.22} \mathrm{Fe}_{1.78} \mathrm{O}_{3} \\
\mathrm{AlO}(\mathrm{OH}) \\
\mathrm{TiO}_{2}\end{array}$ \\
\hline
\end{tabular}



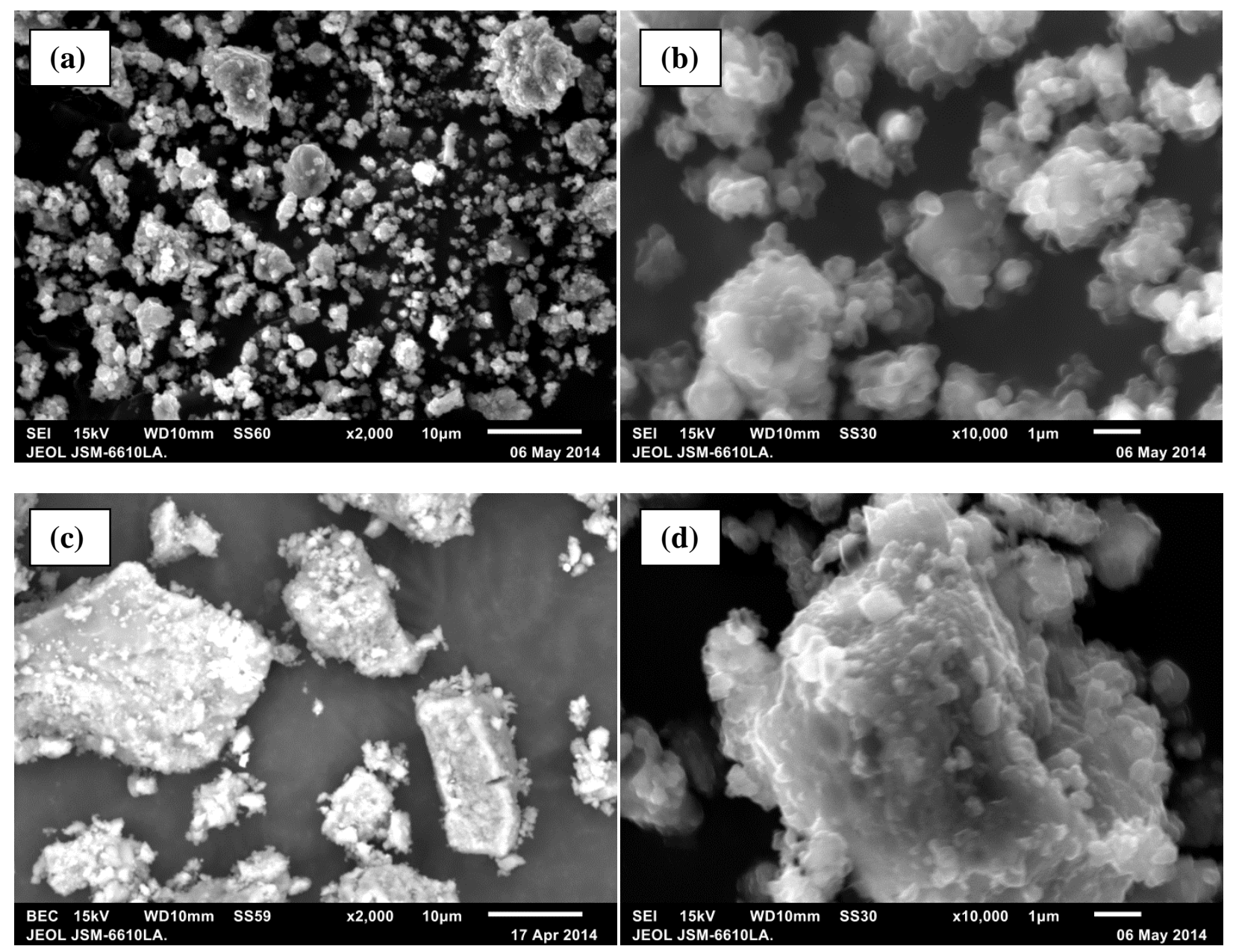

Figure 22: SEM micrographs of RMS4 at (a) 2000 and, (b) 10000 magnification; and BS2 at (c) 2000 and, (d) 10000 magnification.

Figure 22 compares SEM images of RMS4 and BS2 which were the strongest geopolymer for both materials. RMS4 particles are dominantly microstructures of uneven shapes that actually were built from combination of smaller particles with sizes 0.5 to $10 \mu \mathrm{m}$ in diameter (Fig. 22(a)). Observing the BS2 images in Figure 22(c) and 22(d), most occur as single particles with angular shapes and rounded edges. Their sizes vary between 5 to $10 \mu \mathrm{m}$ in diameter, besides having rather large distances between the particles as seen in Figure 22(c). 
The results of EDS analyses of RMS2 and BS2 obtained from area shown in Figure 22 are tabulated in Table 11. In both samples, the major elements that make up the geopolymer backbone $(\mathrm{O}, \mathrm{Na} \mathrm{Al}$, and $\mathrm{Si})$ are observed with high mass and atomic percentages. In addition, the mass percentage of Fe in RMS4 appears to be fairly high, comparable to the geopolymer backbone elements. The presence of Fe in BS2 is not as high as in RMS4 but still noticeable.

\begin{tabular}{|c|c|c|c|c|}
\hline \multirow{2}{*}{ Elements } & \multicolumn{2}{|c|}{ RMS4 } & \multicolumn{2}{c|}{ BS2 } \\
\cline { 2 - 5 } & Mass \% & Atom \% & Mass \% & Atom \% \\
\hline $\mathrm{O}$ & 34.3 & 51.1 & 35.8 & 49.1 \\
$\mathrm{Na}$ & 11.5 & 11.9 & 12.3 & 11.8 \\
$\mathrm{Mg}$ & 0.1 & 0 & - & - \\
$\mathrm{Al}$ & 14.1 & 12.5 & 15.4 & 12.6 \\
$\mathrm{Si}$ & 16.3 & 13.9 & 31.2 & 24.4 \\
$\mathrm{P}$ & 0.2 & 0.2 & 0.2 & 0.1 \\
$\mathrm{~S}$ & 0.4 & 0.3 & - & - \\
$\mathrm{Ca}$ & 0.5 & 0.3 & 0.2 & 0.1 \\
$\mathrm{Ti}$ & 2.6 & 1.3 & - & - \\
$\mathrm{Fe}$ & 20.0 & 8.5 & 4.9 & 1.9 \\
\hline Total & 100 & 100 & 100 & 100 \\
\hline
\end{tabular}

Table 11: EDS global analyses of RMS4 and BS2 shown in Fig. 19.

The difference of Fe content in RMS4 and RMS2 is consistent with the view of Fe distribution in geopolymers presented in Figure 23. It can be seen that the Fe content in RMS4 is more pronounced and concentrated in small aggregates, whereas the Fe in BS2 is evenly distributed throughout the sample. 


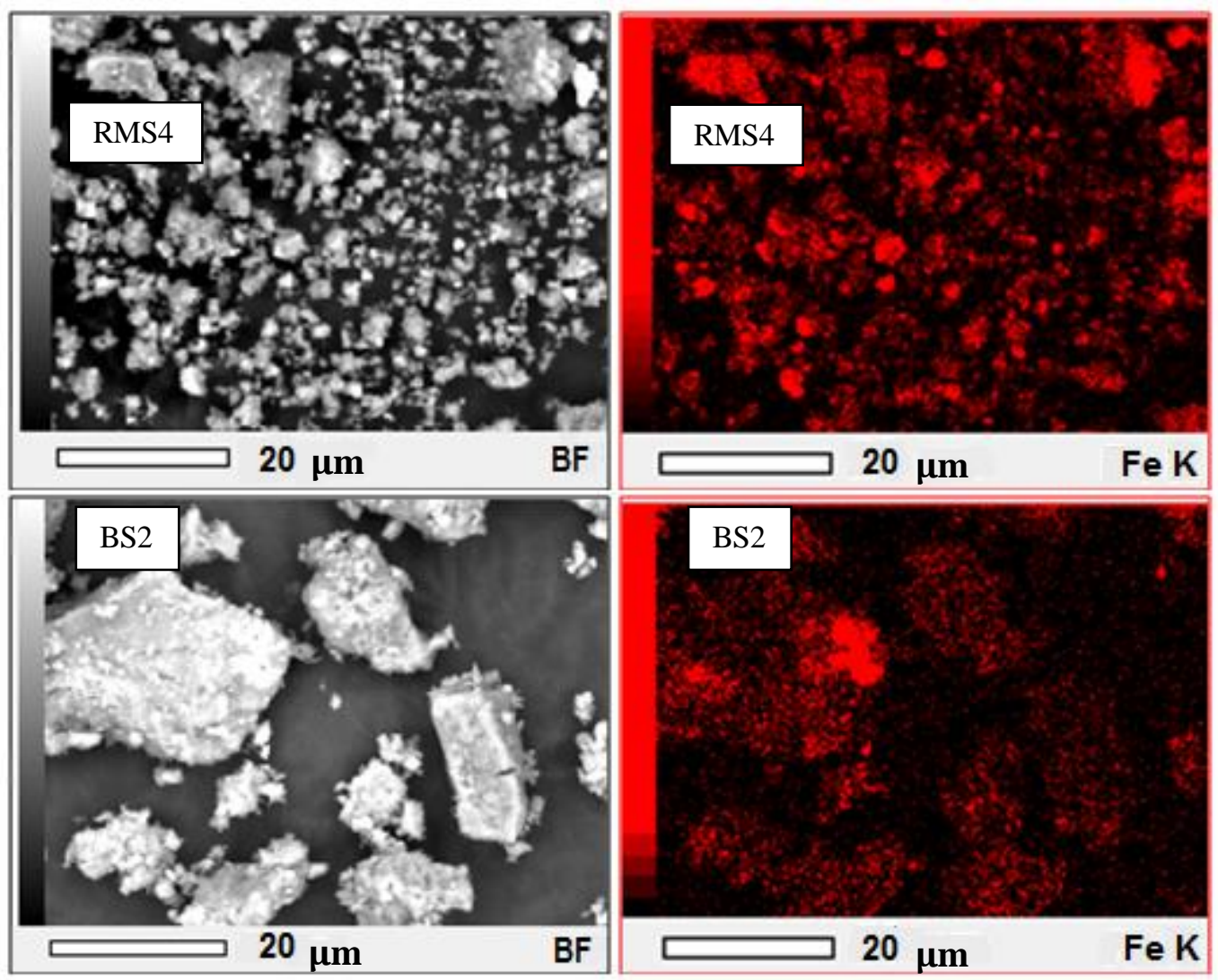

Figure 23: SEM micrographs with EDS elemental mapping of Fe in RMS4 and BS2.

\section{NMR spectroscopy of red mud geopolymers}

Figure 24 shows the ${ }^{27} \mathrm{Al}$ MAS NMR spectra of the red mud raw materials and red mud geopolymers. All these spectra contain a large number of intense spinning side bands resulting from the high concentration of paramagnetic species (iron) present. Both the as-received and calcined red mud show peaks at $61 \mathrm{ppm}$ of similar intensity, arising from tetrahedral aluminium [56, 57]. Another less-intense peak at $8 \mathrm{ppm}$ in the as-received red mud (Fig 24(a)) is due to octahedral aluminium [56]; in the calcined red mud, this peak shifts to $3 \mathrm{ppm}$ and becomes less intense (Fig. 24 (b). The crystal structure of the aluminium mineral boehmite is orthorhombic dipyramidal containing octahedral aluminium, which is destroyed upon heating, explaining the weakening of the octahedral peak intensity. The origin of the tetrahedral peaks in the as-received 
and calcined red mud is less obvious; since the hydrated minerals materials contain only octahedral Al, the tetrahedral Al may arise from one of the transition aluminas (e.g. $\gamma, \theta$ or $\kappa$ alumina) which contain both tetrahedral and octahedral aluminium [56]. These phases tend to have broad and poorly-defined XRD traces, and can easily be overlooked in the X-ray traces.

Upon conversion of the red mud to the various geopolymers, all of the NMR spectra contain both tetrahedral and octahedral aluminium (Fig. 24), but the amount of octahedral aluminium varies, samples RMS4 (Fig. 24(f)) and RMS6 (Fig. 24(h)) containing the least amount of Al(VI). Since the geopolymer structure ideally contains only tetrahedral Al, those samples with the greatest amount of tetrahedral aluminium should have formed the best (strongest) geopolymers. This is illustrated in the case of RMS1 (Fig. 24(c), in which the tetrahedral to octahedral ratio is relatively less than in RMS2 (Fig. 24(d)), and the latter has the higher compressive strength of the two. The same trend is seen in samples RMS3 and RMS4 (Figs. 24(e) and (f)) which contain strong tetrahedral resonances and display good compressive strengths, particularly the latter. However, the relative amount of tetrahedral aluminium is not the only factor influencing the compressive strength, since on this basis sample RMS6 (Fig. 24(h)) should have excellent strength, whereas it is one of the weakest samples, probably due to the presence of drying cracks. 


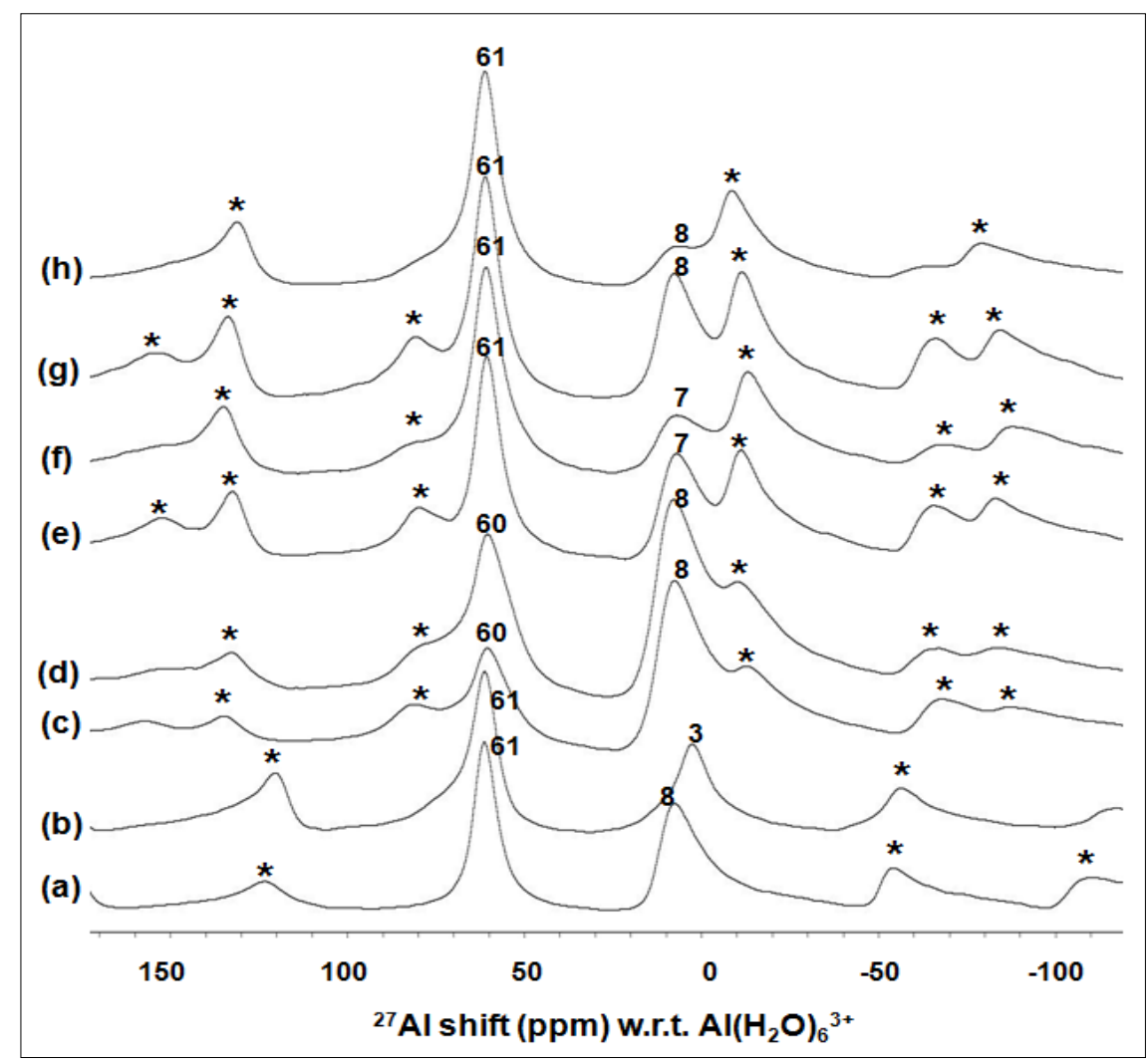

Figure 24: ${ }^{27} \mathrm{Al}$ NMR spectra of red mud; (a) = Red mud raw, (b) = red mud $500{ }^{\circ} \mathrm{C},(\mathrm{c})=$ RMS1, (d) = RMS2, (e) = RMS3, (f) = RMS4, (g) = RMS5, (h) = RMS6. The asterisks denote spinning side bands.

The presence of iron exerted a greater effect on the ${ }^{29} \mathrm{Si}$ spectra, which were very noisy and in some cases (the raw and calcined red mud and samples RMS3 and RMS5) no signal could be obtained at all. All the ${ }^{29} \mathrm{Si}$ spectra of the red mud geopolymers (Fig. 25) show a single broad Si resonance in the -97 to $-108 \mathrm{ppm}$ range, corresponding to $\mathrm{Si}^{4+}$ ion present in tetrahedral sites. In addition RMS6 shows a resonance peak at $-82 \mathrm{ppm}$ previously reported in a Fe-containing geopolymer [58]. The poor quality of these spectra prevents them from yielding any further useful information. 


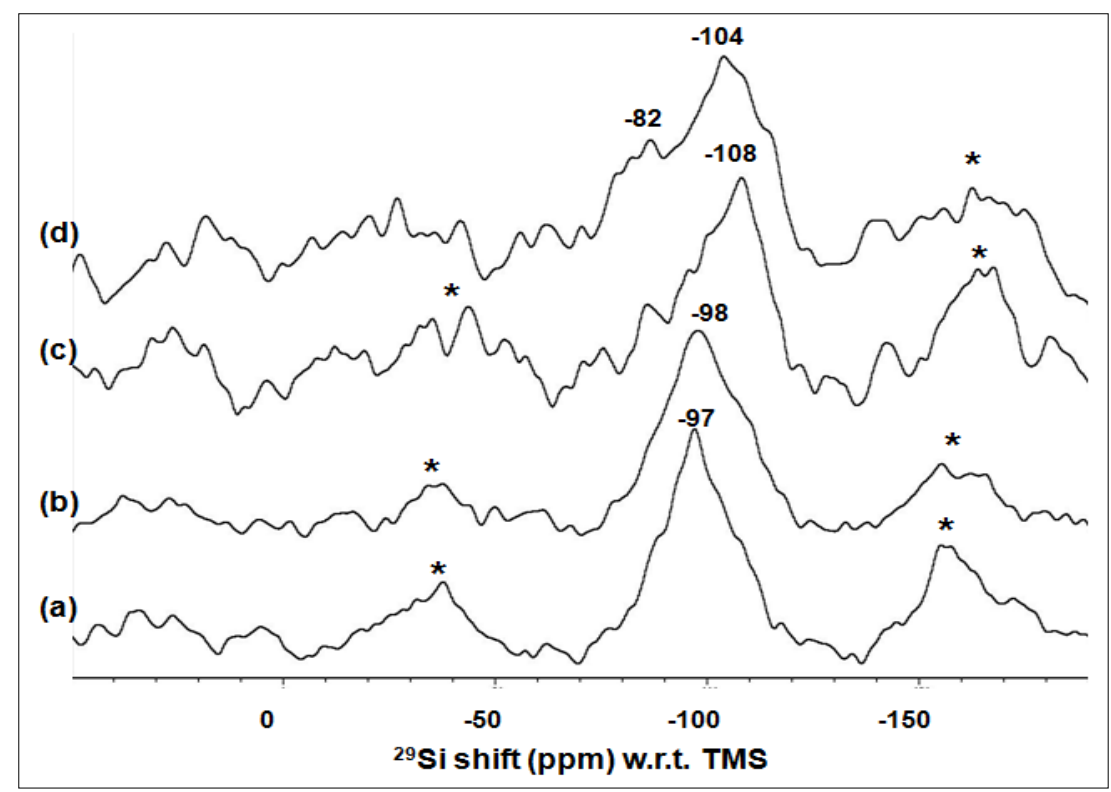

Figure 25: ${ }^{29}$ Si NMR spectra of red mud; (a) = RMS1, (b) = RMS2, (c) = RMS4, (d) = RMS6. Asterisks denote spinning side bands.

From the comparative analysis of ${ }^{27} \mathrm{Al}$ and ${ }^{29} \mathrm{Si}$ MAS NMR spectra, it can be concluded that the degree of geopolymerisation increases from RMS6 to RMS5 to RMS3 to RMS4. However the mechanical strengths of RMS5 and RMS6 are much lower than that of RMS1 and RMS2 whose ${ }^{27} \mathrm{Al}$ MAS NMR spectra did not satisfy the general trend of geopolymers. Generally the ${ }^{27} \mathrm{Al}$ NMR spectra of geopolymers show a broad tetrahedrally-coordinated Al [55]. Samples RMS1 and RMS2 did not meet this requirement hence it can be concluded that geopolymerization of these samples was the least complete. 


\section{NMR spectroscopy of bauxite geopolymers}

The ${ }^{27} \mathrm{Al}$ NMR spectra of the bauxite starting materials and the resulting geopolymers are shown in Figure 26. It can be seen from Figure 26(a) that the $\mathrm{Al}$ in the raw bauxite exists mainly in octahedral sites $[56,59]$, as in gibbsite and boehmite in which the resonance peak occurs at about 9 ppm [56]. Heat treatment of the bauxite removed these minerals, reducing the intensity of the octahedral peak (Figure 26(b)).

Geopolymerisation of the bauxite produced varying amounts of tetrahedrally-coordinated $\mathrm{Al}$, indicated by the peak at 58-60 ppm. On the assumption that the relative amount of tetrahedral $\mathrm{Al}$ is an indicator of the degree of geopolymerization, sample BS1 (Fig. 26(c)), should be a reasonable geopolymer but not as good as BS2, which contains much more tetrahedrallycoordinated Al (Fig. 26(d)). However the spectrum of BS2 is very broad and non-crystalline, such that only the shoulders of spinning side band are seen. In fact, the compressive strength of samples BS1 and BS2 are similar; suggesting that the presence of drying cracks in the latter might have reduced its compressive strength below what would have been expected from the NMR spectra alone. The importance of the additional factor of drying cracks is borne out by sample BS4, whose NMR spectrum (Fig. 26(f)) might suggest a reasonable degree of geopolymerization, but whose compressive strength could not be measured due to the presence

of extensive cracking. The spectrum of sample BS5 (Fig. 26(g)) contains a very sharp tetrahedral Al resonance, the narrow line width of which is consistent with a more crystalline phase such as a zeolite. Zeolite A was indeed observed in this sample by XRD. 


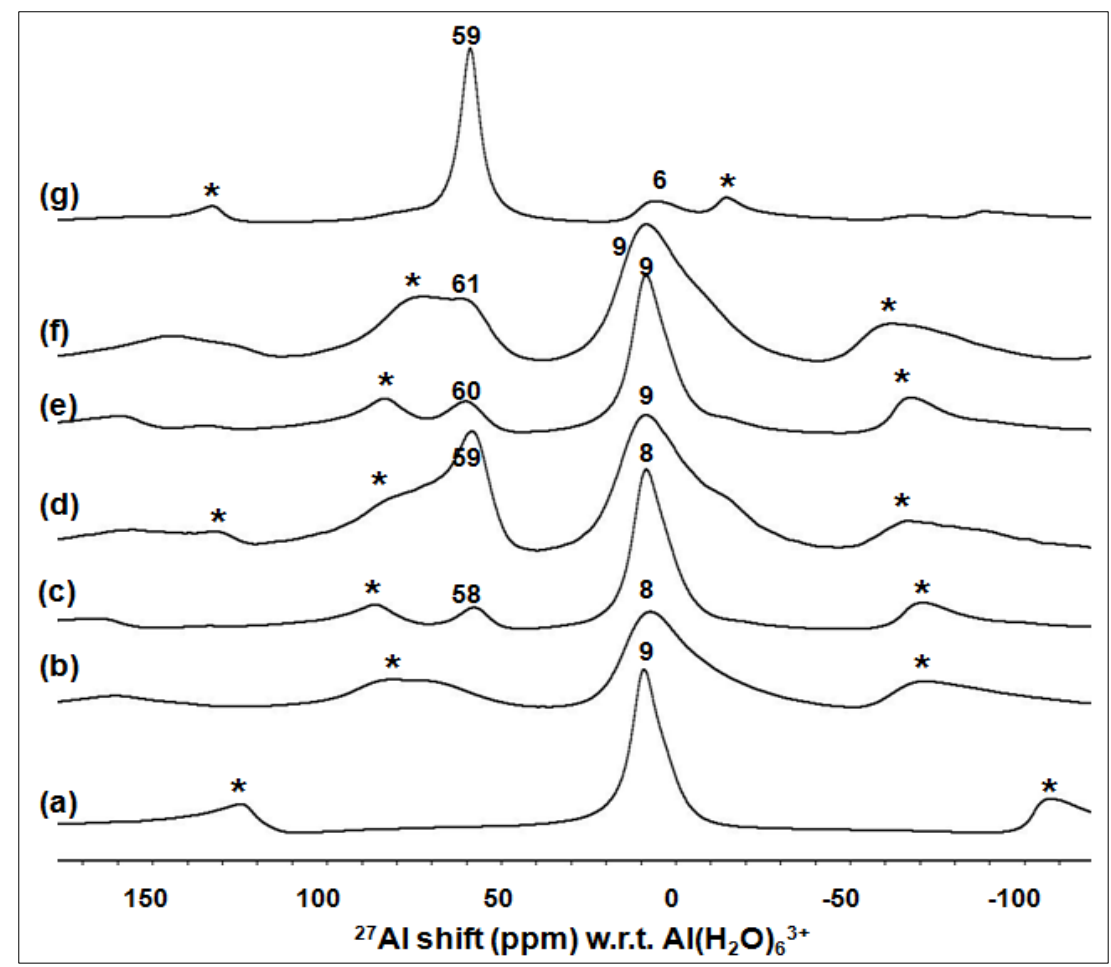

Figure 26: ${ }^{27} \mathrm{Al}$ NMR spectra of bauxite; (a) = bauxite raw, (b) = bauxite $500^{\circ} \mathrm{C},(\mathrm{c})=\mathrm{BS} 1$, $(\mathrm{d})=\mathrm{BS} 2,(\mathrm{e})=\mathrm{BS3},(\mathbf{f})=\mathrm{BS} 4,(\mathrm{~g})=\mathrm{BS5}$. Asterisks denote spinning side bands.

The ${ }^{29} \mathrm{Si}$ NMR spectra of bauxite and its geopolymer are shown in Figure 27. As with red mud, the spectra are extremely noisy and of poor quality, and no signal could be obtained from calcined bauxite, nor from sample BS3. The Si spectrum of BS1 (Fig. 27(b)) revealed a main resonance peak at $-96 \mathrm{ppm}$ with shoulders at $-87 \mathrm{ppm}$ and $-105 \mathrm{ppm}$. The shoulder at $-87 \mathrm{ppm}$ suggests the presence of $\mathrm{Si}-\mathrm{O}-(\mathrm{Al})_{4}$ as found in silicate structures more completely coordinated to $\mathrm{Al}$ than in conventional geopolymers, in which the principal resonance is at about $-91 \mathrm{ppm}$ $[46,56]$, but the broadness of this resonance envelope makes further interpretation inadvisable. The shoulder at -105 ppm suggests the presence of unreacted silica [56]. The Si spectrum of BS5 (Fig. 27(e)) shows a very sharp resonance peak at $-89 \mathrm{ppm}$ which is typical of a crystalline zeolite $[56,60]$. The small broad peak at -109 ppm is associated with amorphous $\mathrm{SiO}_{2}$ [61] from the silica fume that was added to this mixture and has only partially reacted. 


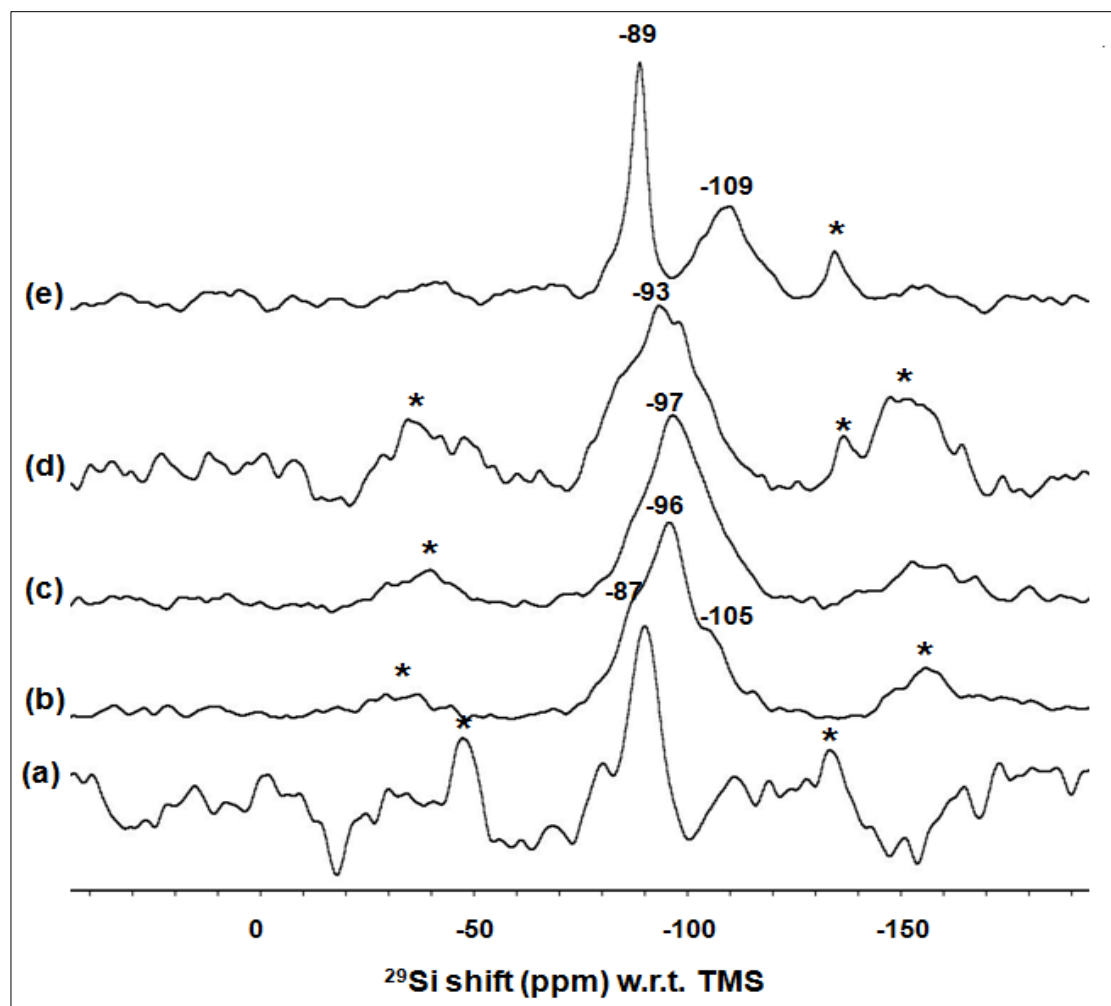

Figure 27: ${ }^{29}$ Si NMR spectra of bauxite; (a) = bauxite raw, (b) = BS1, (c) = BS2, (d) = BS4, (e) = BS5. Asterisks denote spinning side bands 


\section{Conclusions and future works}

In this work, the geopolymerisation of the red mud and its parent bauxite were investigated. The effect of water content to the geopolymer strength was crucial in the process, proven by the samples with high water to sodium ratio having low mechanical strength. The highest compressive strength obtained for red mud and bauxite were $58 \mathrm{MPa}$ and $28 \mathrm{MPa}$ respectively. These geopolymers were made from calcined materials with water to sodium ratio of 11.81 and 8.82 ; hence the increase of materials reactivity when it is calcined was also evidenced. In future, Mössbauer spectroscopy may be used to study the influence of Fe on the geopolymerisation. The presents of drying cracks may be reduced or prevented by applying small amount of glycerol to the geopolymer. From this project it was believed that it is possible to produce useful materials from the red mud and bauxite itself, without adding too much of other materials. 


\section{References}

1. Primary Aluminium Consumption 2011-2013. 2014 [cited 201415 March]; Available from: http://www.alueurope.eu/consumption-primary-aluminium-consumption-in-worldregions/.

2. Adams, W. Aluminium Analysis and forecast Q1 213. 2013 [cited 2013 March 15 ${ }^{\text {th }}$ ]; Available from: $\quad$ http://www.fastmarkets.com/aluminium-analysis-andresearch/aluminium-analysis-forecast-q1-213.

3. Rai, S., et al., Neutralization and utilization of red mud for its better waste management. Archives of Environmental Science, 2012. 6: p. 13-33.

4. Sutar, H., et al., Progress of Red Mud Utilization: An Overview. American Chemical Science Journal, 2014. 4(3): p. 255-279.

5. Burke, I.T., et al., Speciation of Arsenic, Chromium, and Vanadium in Red Mud Samples from the Ajka Spill Site, Hungary. Environmental Science \& Technology, 2012. 46(6): p. 3085-3092.

6. Renforth, P., et al., Contaminant mobility and carbon sequestration downstream of the Ajka (Hungary) red mud spill: The effects of gypsum dosing. Science of the Total Environment, 2012. 421-422: p. 253-259.

7. Ádám, J., et al., The Kolontár Report. Causes and Lessons from the Red Mud Disaster, B. Jávor and M. Hargitai, Editors. 2011: Budapest. p. 156.

8. Tran, M. Hungary toxic sludge spill an 'ecological catastrophe' says government. 2010 [cited $2012 \quad 25 \quad$ July]; Available http://www.guardian.co.uk/world/2010/oct/05/hungary-toxic-sludge-spill.

9. Taylor, A. A Flood of Red Sludge, One Year Later. 2011 [cited 201225 July]; Available from: $\quad$ http://www.theatlantic.com/infocus/2011/09/a-flood-of-red-sludge-one-yearlater/100158/.

10. Tibor Navracist, D. The company responsible for the Hungarian red sludge tragedy has received a record penalty. 2011 [cited 201225 July]; Available from: http://www.kormany.hu/en/ministry-of-public-administration-and-justice/news/the- 
company-responsible-for-the-hungarian-red-sludge-tragedy-has-received-a-recordpenalty.

11. Power, G., M. Gräfe, and C. Klauber, Bauxite residue issues: I. Current management, disposal and storage practices. Hydrometallurgy, 2011. 108(1-2): p. 33-45.

12. Liu, D.-Y. and C.-s. Wu, Stockpiling and Comprehensive Utilization of Red Mud Research Progress. Materials, 2012. 5: p. 1232-1246.

13. Poulin, É., J.-F. Blais, and G. Mercier, Transformation of red mud from aluminium industry into a coagulant for wastewater treatment. Hydrometallurgy, 2008. 92(1-2): p. $16-25$.

14. Klauber, C., M. Gräfe, and G. Power, Bauxite residue issues: II. options for residue utilization. Hydrometallurgy, 2011. 108(1-2): p. 11-32.

15. Komnitsas, K. and D. Zaharaki, Utilisation of low-calcium slags to improve the strength and durability of geopolymers., in Geopolymers: Structures, Processing, Properties and Industrial Applications J.L. Povis and J.S.J. van Deventer, Editors. 2009. p. 343-375.

16. He, J., et al., The strength and microstructure of two geopolymers derived from metakaolin and red mud-fly ash admixture: A comparative study. Construction and Building Materials, 2012. 30(0): p. 80-91.

17. Zhang, G., J. He, and R.P. Gambrell, Synthesis, Characterization, and Mechanical Properties of Red Mud-Based Geopolymers. Transportation Research Record: Journal of the Transportation Research Board, 2010. 2167: p. 1-9.

18. Kumar, A. and S. Kumar, Development of paving blocks from synergistic use of red mud and fly ash using geopolymerization. Construction and Building Materials, 2013. 38(0): p. 865-871.

19. Mucsi, G., et al., Development of geopolymer using industrial waste materials, in 9th International Conference “Environmental Engineering”2014: Vilnius, Lithuania.

20. Dimas, D., I.P. Giannopoulou, and D. Panias, UTILIZATION OF ALUMINA RED MUD FOR SYNTHESIS OF INORGANIC POLYMERIC MATERIALS. Mineral Processing and Extractive Metallurgy Review: An International Journal, 2009. 30(3): p. 211-239.

21. Mira, V., et al., UTILIZATION OF GEOPOLYMERIZATION FOR OBTAINING CONSTRUCTION MATERIALS BASED ON RED MUD. Materials and Technology, 2013. 47(1): p. 99-104. 
22. He, J., et al., Synthesis and characterization of red mud and rice husk ash-based geopolymer composites. Cement and Concrete Composites, 2013. 37(0): p. 108-118.

23. Ye, N., et al., Synthesis and Characterization of Geopolymer from Bayer Red Mud with Thermal Pretreatment. Journal of the American Ceramic Society, 2014: p. n/a-n/a.

24. Ivana, B., et al., The Influence of Raw Mixture and Activators Characteristics on RedMud based Geopolymers. Research Journal of Chemistry and Environment, 2013. 17(1): p. 34-40.

25. Yao, X., et al., Geopolymerization process of alkali-metakaolinite characterized by isothermal calorimetry. Thermochimica Acta, 2009. 493(1-2): p. 49-54.

26. Joshi, S.V. and M.S. Kadu, Role of Alkaline Activator in Development of Eco-friendly Fly Ash Based Geo Polymer Concrete. International Journal of Environmental Science and Development, 2012. 3(5): p. 417-421.

27. Allahverdi, A., K. Mehrpour, and E.N. Kani, Investigating the possibility of utilizing pumice-type natural pozzonal in production of geopolymer cement. Ceramic Silik 2008, 2007. 52(1): p. 16-23.

28. Duxson, P., et al., Geopolymer technology: the current state of the art. Journals of Materials Science, 2007. 42(9): p. 2917-2933.

29. Yunsheng, Z., et al., Synthesis and heavy metal immobilization behaviors of slag based geopolymer. J Hazard Mater, 2007. 143(1-2): p. 206-13.

30. Liu, X., et al., Structural investigation relating to the cementitious activity of bauxite residue - Red mud. Cement and Concrete Research, 2011. 41(8): p. 847-853.

31. Cheng, T.W. and J.P. Chiu, Fire-resistant geopolymer produced by granulated blast furnace slag. Minerals Engineering, 2003. 16(3): p. 205-210.

32. ŠKVÁRA, F., T. JÍLEK, and L. KOPECKÝ, Geopolymer materials based on fly ash. Ceramics-Silikaty 2005. 49(3): p. 195-204.

33. Škvára, F., et al., GEOPOLYMER CONCRETE - AN ANCIENT MATERIAL TOO? Ceramics - Silikáty, 2008. 52(4): p. 296-298.

34. Worrell, E., et al., Carbon dioxide emission from the global cement industry. Annual Reviews of Energy and the Environment, 2001. 26: p. 303-329.

35. Barbosa, V.F.F. and K.J.D. MacKenzie, Synthesis and thermal behaviour of potassium sialate geopolymers. Materials Letters, 2003. 57(9-10): p. 1477-1482. 
36. Zuhua, Z., et al., Role of water in the synthesis of calcined kaolin-based geopolymer. Applied Clay Science, 2009. 43(2): p. 218-223.

37. Giannopoulou, I., et al., Utilization of metallurgical solid by-products for the development of inorganic polymeric construction materials. Global NEST Journal, 2009. 11(2): p. 127-136.

38. Dimas, D.D., I.P. Giannopoulou, and D. Panias, Utilization of alumina red mud for synthesis of inorganic polymeric materials. Mineral Processing and Extractive Metallurgy Review, 2009. 30(3): p. 211-239.

39. Hardjito, D., et al., On the Development of Fly Ash-Based Geopolymer Concrete. ACI Materials Journal, 2004. 101(6): p. 467-472.

40. Panias, D., I.P. Giannopoulou, and T. Perraki, Effect of synthesis parameters on the mechanical properties of fly ash-based geopolymers. Colloids and Surfaces A: Physicochemical and Engineering Aspects, 2007. 301(1-3): p. 246-254.

41. Perera, D.S., et al., Fe speciation in geopolymers with Si/Al molar ratio of $\sim 2$. Journal of the European Ceramic Society, 2007. 27(7): p. 2697-2703.

42. Bell, J.L. and W.M. Kriven, Formation of an Iron-Based Inorganic Polymer (Geopolymer), in Mechanical Properties and Performance of Engineering Ceramics and Composites IV2009, John Wiley \& Sons, Inc. p. 301-312.

43. Onisei, S., et al., Synthesis of inorganic polymers using fly ash and primary lead slag. Journal of Hazardous Materials, 2012. 205-206(0): p. 101-110.

44. Pontikes, Y., et al., Slags with a high Al and Fe content as precursors for inorganic polymers. Applied Clay Science, 2013. 73(0): p. 93-102.

45. Lemougna, P.N., et al., The role of iron in the formation of inorganic polymers (geopolymers) from volcanic ash: a 57Fe Mössbauer spectroscopy study. Journal of Materials Science, 2013. 48: p. 5280-5286.

46. Barbosa, V.F.F., K.J.D. MacKenzie, and C. Thaumaturgo, Synthesis and characterisation of materials based on inorganic polymers of alumina and silica: sodium polysialate polymers. International Journal of Inorganic Materials, 2000. 2(4): p. 309-317.

47. Wu, C.-s. and D.-y. Liu, Mineral Phase and Physical Properties of RedMud Calcined at Different Temperatures. Hindawi Publishing Corporation, Journal of Nanomaterials, 2012(Article ID 628592): p. 1-6. 
48. PerkinElmer. Characterization of Polymers Using TGA. 2014 [cited 2014 March 13]; Available from: $\quad$ http://www.perkinelmer.com/CMSResources/Images/44132088APP CharacterizationofPolymersUsingTGA.pdf.

49. Mackenzie, R.C., The Thermal Investigation of Clays. Mineralogical Society Monograph, 1952.

50. Davidovits, J., Geopolymers - inorganic polymeric new materials. Journal of Thermal Analysis, 1991. 37(8): p. 1633-1656.

51. $\mathrm{Xu}, \mathrm{H}$. and J.S.J. Van Deventer, Effect of source materials on geopolymerization.

. Industrial \& Engineering Chemistry Research, 2003. 42(8): p. 1698-1706.

52. Hajjaji, W., et al., Composition and technological properties of geopolymers based on metakaolin and red mud. Materials \& Design, 2013. 52(0): p. 648-654.

53. Al Bakri, M.M., et al., Review on fly ash-based geopolymer concrete without Portland Cement. Journal of Engineering and Technology Research, 2011. 3(1): p. 1-4.

54. Weng, L. and K. Sagoe-Crentsil, Dissolution processes, hydrolysis and condensation reactions during geopolymer synthesis: part I - low Si/Al ratio systems. Journal of Materials Science, 2007. 42(9): p. 2997-3006.

55. Barbosa, V.F.F. and K.J.D. MacKenzie, Thermal Behaviour of Inorganic Polymers and Composites Derived from Sodium Polysialate. Materials Research Bulletin, 2003. 38: p. 319-331.

56. MacKenzie, K.J.D. and M.E. Smith, Multinuclear Solid-state NMR of Inorganic Materials

ed. R.W. Cahn2002, The Netherlands.

57. Kriven, W.M., et al., Developments in Strategic Materials and ComputationaLDesign III, 2012, The American Ceramic Society.

58. Kulshreshtha, S.K., et al., Iron oxide nanoparticles in NaA zeolite cages. Solid State Sciences, 2013. 21: p. 44-50.

59. Liu, X., et al., Micro-structural characterization of the hydration products of auxite-calcination-method red mud-coal gangue based cementitious materials Journal of Hazardous Materials, 2013. 262: p. 428-438. 
60. Bekkum, H.v., et al., Solid state NMR spectroscopy applied to zeolites, in Introduction to Zeolite Science and Practice G. Engelhardt, Editor 2001. p. 387-415.

61. Guo, J.-G., et al., The 29Si and 27 Al MAS NMR Spectra of Mullite Sintered at Different Temperatures. Chinese Science Bulletin, 1990. 36(17): p. 1467-1470. 